\title{
Modifying Yeast Tolerance to Inhibitory Conditions of Ethanol Production Processes
}

\author{
Luis Caspeta $^{1 *}$, Tania Castillo ${ }^{1}$ and Jens Nielsen ${ }^{2,3,4}$ \\ ${ }^{1}$ Centro de Investigación en Biotecnología, Universidad Autónoma del Estado de Morelos, Cuernavaca, Mexico, \\ ${ }^{2}$ Novo Nordisk Foundation Center for Biosustainability, Chalmers University of Technology, Gothenburg, Sweden, \\ ${ }^{3}$ Department of Biology and Biological Engineering, Chalmers University of Technology, Gothenburg, Sweden, ${ }^{4}$ Novo \\ Nordisk Foundation Center for Biosustainability, Hørsholm, Denmark
}

OPEN ACCESS

Edited by:

Hilal Taymaz Nikerel, Bogazici University, Turkey

Reviewed by:

Caroline Evans,

University of Sheffield, UK

Steven W. Gorsich,

Central Michigan University, USA

Nianshu Zhang,

University of Cambridge, UK

${ }^{*}$ Correspondence:

Luis Caspeta

luis.caspeta@uaem.mx

Specialty section: This article was submitted to

Systems Biology,

a section of the journal Frontiers in Bioengineering and Biotechnology

Received: 16 August 2015 Accepted: 28 October 2015 Published: 11 November 2015

Citation:

Caspeta L, Castillo T and Nielsen J (2015) Modifying Yeast Tolerance to Inhibitory Conditions of Ethanol Production Processes.

Front. Bioeng. Biotechnol. 3:184. doi: 10.3389/fbioe.2015.00184
Saccharomyces cerevisiae strains having a broad range of substrate utilization, rapid substrate consumption, and conversion to ethanol, as well as good tolerance to inhibitory conditions are ideal for cost-competitive ethanol production from lignocellulose. A major drawback to directly design S. cerevisiae tolerance to inhibitory conditions of lignocellulosic ethanol production processes is the lack of knowledge about basic aspects of its cellular signaling network in response to stress. Here, we highlight the inhibitory conditions found in ethanol production processes, the targeted cellular functions, the key contributions of integrated -omics analysis to reveal cellular stress responses according to these inhibitors, and current status on design-based engineering of tolerant and efficient $S$. cerevisiae strains for ethanol production from lignocellulose.

Keywords: yeast, stress tolerance, cellular stress response, inhibitory environment, ethanol production process, design-based engineering, integrated -omics analysis

\section{INTRODUCTION}

Microbial fermentation of sugars from sugarcane and corn starch to ethanol is the source of around 100 billion liters of fuel ethanol annually produced in the world using Saccharomyces cerevisiae. There is also much interest in the use of lignocellulose as a feedstock for future production of ethanol, since this source is much more abundant and, most important, it does not compete with food for supplies (Lynd et al., 1991; Caspeta et al., 2013). However, one of the major bottlenecks for lignocellulose conversion to ethanol is that the related production processes should be economically competitive, a condition that is in detriment of yeast performance, since it must face high concentrations of toxic chemicals and harmful process conditions, for which extra operations for process conditioning to yeast tolerance are economically and energetically prohibited (Caspeta et al., 2013, 2014a). Thus, yeast cells can be exposed to inhibitory concentrations of toxic chemicals and low $\mathrm{pH}$ resulted from thermo-chemical pretreatment of lignocellulose. Furthermore, saccharification and fermentation of sugar polymers exposed S. cerevisiae to high temperatures, elevated osmolarity, and high concentrations of ethanol (Garay-Arroyo et al., 2004; Caspeta et al., 2014a). The former conditions are useful to reduce contamination and cooling efforts as well as to decrease energy utilization during downstream processing and to decrease enzyme loadings concomitant with lower production costs (Caspeta et al., 2014a).

Microorganisms capable of resisting conditions of lignocellulose ethanol production processes whereas maintaining high metabolic activity are desirable. Microbial strains with these characteristics 
can be isolated from natural habitats where they have been evolving these traits for a long time (Ballesteros et al., 1991; Edgardo et al., 2008; Field et al., 2015). Another option is to generate tolerant phenotypes in model organisms like $S$. cerevisiae. This requires the augmentation of limits between the relation of cellular functions and environmental fluctuations, namely to diminish the disturbing effects of inhibitory conditions on cellular functions required for growing and biofuel synthesis. Some of the targeted functions include proteome structure and stability, RNA synthesis and processing, sugar transport, membrane fluidity, and DNA processing, among others (Kültz, 2005).

Yeast and other microorganisms have gene expression and metabolic turnover programs that have been finely adjusted to improve cells fitness in the environmental fluctuations found in their natural environments (Tagkopoulos et al., 2008; Mitchell et al., 2009). Therefore, microorganisms exposed to novel environments may mount erratic non-specific responses leading them to survive or perish. Thus, one can expect that adaptation to novel environments will require the complete reprograming of cellular functions, including gene expression and metabolic turnover, which may not be attainable by multigene modification (Alper and Stephanopoulos, 2009). This is probably more evident due to the fact that stressful conditions - out of those found in the natural environments - will not be anticipated in native signaling networks. However, there is genomic plasticity that allows approaching the hypothesis that cells can acquire new functions or reconfigure macromolecular structures more suitable to new environments. The challenge then is to recognize the genomic rearrangements and the resultant levels of gene expression, according to environmental changes. In this review, we describe basic knowledge about cellular stress response (CSR) and the current strategies for improving yeast tolerance to inhibitory conditions found in lignocellulosic ethanol production processes.

\section{INHIBITORY CONDITIONS OF LIGNOCELLULOSIC ETHANOL PRODUCTION PROCESS}

Lignocellulose is a tightly packed structure of the carbohydrate polymers cellulose and hemicellulose surrounded by the phenolic polymer lignin. Although several processes have been developed thus far for lignocellulose conversion to ethanol, a characteristic one includes the general steps shown in Figure 1. Once the material has been chopped in pieces, a pretreatment step mainly consisting of a thermo-chemical treatment of lignocellulose is used for its hydrolysis into fermentable sugars. These get dissolved in a syrup that can also contain acetic, formic, and levulinic acids, as well as furans and phenolic compounds released during pretreatment (Larsson et al., 1999; Palmqvist and Hahn-Hägerdal, 2000b). Since these chemicals reduce yeast growth and ethanol production (Zaldivar et al., 1999; Larsson et al., 2000; Palmqvist and Hahn-Hägerdal, 2000a), several efforts have been made to avoid their production (Palmqvist and Hahn-Hägerdal, 2000a; Caspeta et al., 2014a). Another option is to reduce their concentrations by different detoxification methods (Palmqvist and Hahn-Hägerdal, 2000a), but extra operations negatively impact energy balance and production costs (Caspeta and Nielsen, 2013).

Whatever the hydrolysis method, this must ensure syrups with high sugar concentrations. Concentrations of fermentable sugars higher than $250 \mathrm{~g} \mathrm{~L}^{-1}$ guarantee ethanol titers above $100 \mathrm{~g} \mathrm{~L}^{-1}$, required to reduce energy consumption and production costs during downstream operations (Haelssig et al., 2008). To reach these concentrations, suspensions with around $416 \mathrm{~g}$ of pretreated lignocellulosic biomass containing $60 \%$ of fermentable sugars - a high gravity suspension will be needed. The resulted syrup would contain high amounts of toxic chemicals as well as elevated amounts of insoluble lignin and cellulose fractions. If saccharification and fermentation of cellulose is performed simultaneously, the high gravity of cellulose/lignin suspension could impair both, enzyme activity and cell growth (Caspeta et al., 2014a). Whereas, performing saccharification and fermentation separately exposes yeast cells to toxic compounds and very high osmolarity.

Performing thermo-chemical hydrolysis at mild conditions reduces toxic compounds formation and can disrupt lignocellulose structure (Pan et al., 2006; Caspeta et al., 2014a), keeping hemicellulose and/or cellulose polymers intact for their further hydrolysis with cellulosic enzymes. Saccharification is costly and highly affected by process temperature and solid loadings (Ingesson et al., 2001; Caspeta et al., 2014a). Most of commercial enzymes have optimal temperatures higher than $45^{\circ} \mathrm{C}$ and the enzymes' industry have been trying to increase it, because of operations at high temperatures are highly desirable to reduce contamination and cooling efforts. This condition, however, limits simultaneous saccharification and fermentation since most of yeast strains do not tolerate temperatures higher than $40^{\circ} \mathrm{C}$.

In summary, S. cerevisiae can be exposed to a number of toxic compounds formed during pretreatment of biomass, e.g., low $\mathrm{pH}$, unusual levels of sugar concentration and solid loadings in cellulose suspensions and hydrolyzates, lethal temperatures occurring in saccharification, and high ethanol concentrations resulting from the fermentation. All these inhibitory conditions affect cellular functions in the different forms as described below.

\section{INHIBITORY EFFECTS OF HARMFUL CONDITIONS OF LIGNOCELLULOSIC ETHANOL PRODUCTION PROCESS}

\section{Inhibitory Effects of Toxic Compounds}

The inhibition of cellular growth and metabolism by toxic compounds formed or released during hydrolysis of lignocellulosic biomass was detailed elsewhere (Palmqvist and Hahn-Hägerdal, 2000b), and summarized in Table 1. Harmfulness of acetic, formic, and levulinic acids depends on extracellular and intracellular $\mathrm{pH}$, membrane permeability, and toxicity of the anionic forms of the acids (Palmqvist and Hahn-Hägerdal, 2000b; Maris et al., 2004). Once the acid goes into yeast cell, the intracellular $\mathrm{pH}$ drops and excessive proton accumulation is pumped out of the cells by various mechanisms, including proton translocation with the plasma membrane $\mathrm{H}^{+}$-ATPase mediated by ATP hydrolysis (Holyoak et al., 1996; Maris et al., 2004). This cellular process can 


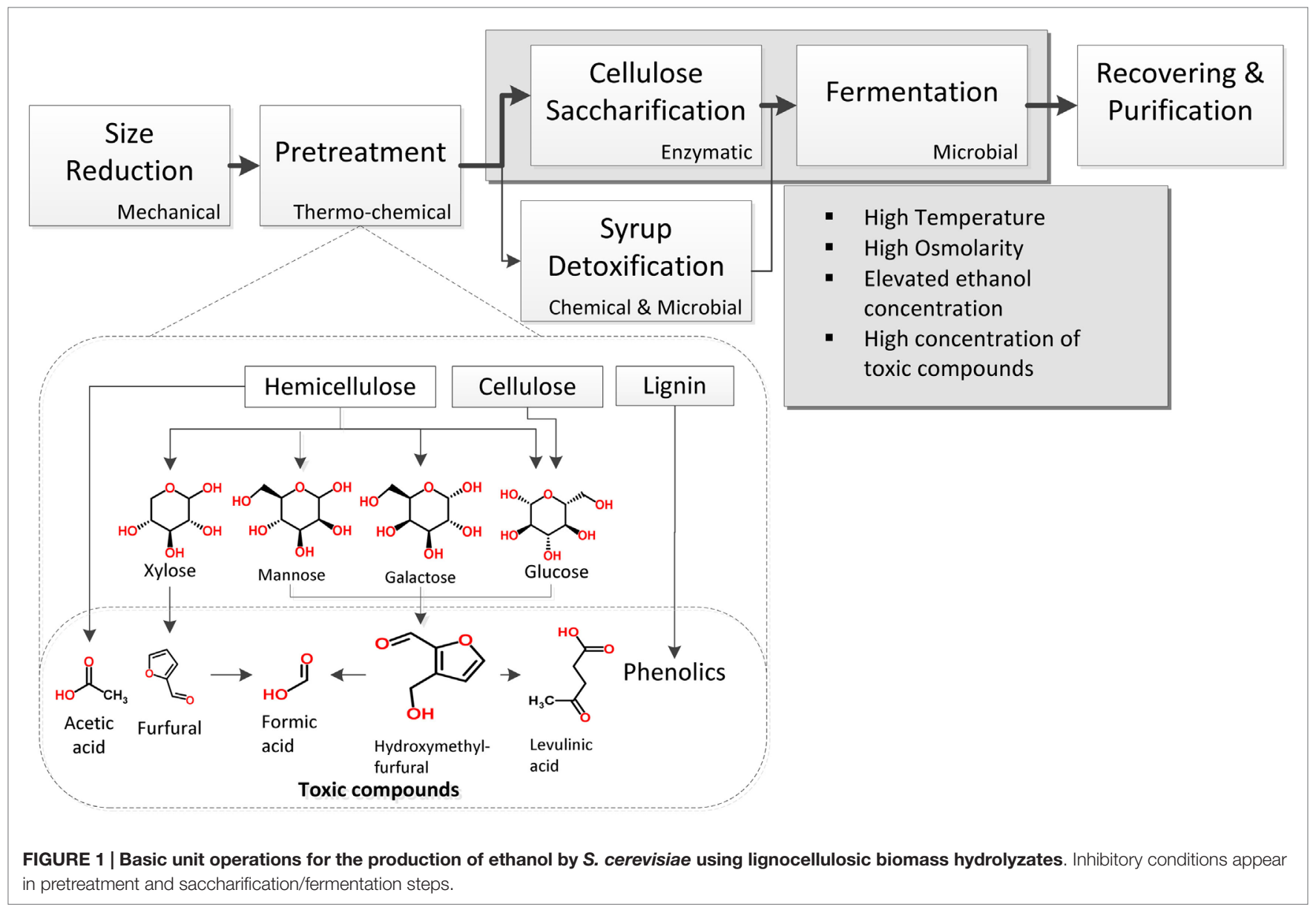

be very intensive in terms of ATP utilization. For example, in presence of sorbic, benzoic, and octanoic acids at $\mathrm{pH} 4.5,5.0$, and 4.0, respectively, a 10-, 4-, and 1.5-fold decrease in intracellular ATP levels can be observed due to increasing energy for maintenance of the internal pH (Viegas and Sá-Correia, 1991; Verduyn et al., 1992; Holyoak et al., 1996), with a concomitant reduction of biomass yields (Viegas and Sá-Correia, 1991; Verduyn et al., 1992). Furthermore, acetic and formic acids, in their anionic forms, are lipophobic and enter to the cell as undissociated forms, which prevail at external $\mathrm{pH}$ values below 4.8 (Casal et al., 1996). Inside the cell, the acid is dissociated and the intracellular $\mathrm{pH}$ decreases. It has been shown that intracellular concentrations higher than $120 \mathrm{mM}$ of acetic acid reduce enolase and phosphoglyceromutase activities by $50 \%$ respect to non-acidic conditions (Pampulha and Loureiro-Dias, 1990). However, evidence suggests that proton exporting is the major contribution for reduced growth rate upon yeast exposition to acids.

The 5-hydroxymethyl furfural (HMF) and 2-furaldehyde (furfural) are formed from thermal oxidation of hexoses and pentoses during pretreatment (Palmqvist and Hahn-Hägerdal, 2000b) - Figure 1. These compounds induce chromatin changes, DNA damage, reduced translation, and inactivation of various glycolytic enzymes (Banerjee et al., 1981; Allen et al., 2010; Ask et al., 2013a) (Table 1). Yeast can metabolize furfural and HMF to their less toxic alcohols by oxidoreductases using $\mathrm{NAD}(\mathrm{P}) \mathrm{H}$ as a cofactor, a metabolic process that occurs at high rates (Diaz De Villegas et al., 1992; Ask et al., 2013a). Their conversion increases the cellular energy for maintenance and reduces the concentration of redox cofactors (Taherzadeh et al., 1999; Sárvári Horváth et al., 2003; Ask et al., 2013a). Thus, this is associated to a reduction of glycerol production and an increase of acetate production during ethanol fermentation in the presence of furfural (Palmqvist et al., 1999a; Sárvári Horváth et al., 2003; Ask et al., 2013b). Results from exposing S. cerevisiae to these chemicals suggested that yeast growth is more sensitive to furfural than to HMF or high ethanol titers (Taherzadeh et al., 1999), because HMF has lower permeability and its conversion is less efficient than furfural (Larsson et al., 1999). Besides, accumulation of reactive oxygen species induced by furfural can damage $S$. cerevisiae mitochondrion and vacuole (Allen et al., 2010). Both compartments regulate redox balance of cytosol and losing their functions can result in a reduction of glucose consumption rates.

When mixtures of acetic acid and furfural are present in the fermentation, the specific growth rate decreased more than the sum of the individual effects (Palmqvist et al., 1999b), suggesting that cells expend higher amounts of energy for excreting 
TABLE 1 | Examples of negative effects of inhibitory conditions found in ethanol production processes on yeast performance.

\begin{tabular}{|c|c|c|}
\hline Stress & Negative effects in the yeast cells & Reference \\
\hline $\begin{array}{l}\text { Exposition to toxic compounds (furfural, HMF, } \\
\text { and phenolic compounds) }\end{array}$ & $\begin{array}{l}\text { Chromatin changes, DNA damage, and reduction of translation } \\
\text { activity } \\
\text { Enzyme inactivation } \\
\text { Reduction of the intracellular concentrations of NAD(P)H } \\
\text { Negative effects on sorting and signaling functions } \\
\text { Reactive oxygen species formation } \\
\text { Low biomass yields }\end{array}$ & $\begin{array}{l}\text { Allen et al. (2010), Ask et al. (2013a) } \\
\text { Ask et al. (2013b) } \\
\text { Keweloh et al. (1990) } \\
\text { Larsson et al. (1999) }\end{array}$ \\
\hline Exposition to organic acids & $\begin{array}{l}\text { Reduction of biomass yields } \\
\text { Decrease of the intracellular ATP levels, concomitant to an } \\
\text { increase of the maintenance energy } \\
\text { Drop of the intracellular pH } \\
\text { Reduction of enzymatic activities }\end{array}$ & $\begin{array}{l}\text { Viegas and Sá-Correia (1991) } \\
\text { Holyoak et al. (1996) } \\
\text { Pampulha and Loureiro-Dias (1990) }\end{array}$ \\
\hline Exposition to ethanol & $\begin{array}{l}\text { Impairment of cellular wall permeability } \\
\text { Disruption of sorting and signaling functions, with an increment of } \\
\text { the cell size } \\
\text { Induction of petite mutants without mitochondrial DNA }\left(\mathrm{rho}^{\circ}\right) \\
\text { Reduction of metabolic activity } \\
\text { Impairment of acid resistance }\end{array}$ & $\begin{array}{l}\text { Kubota et al. (2004) } \\
\text { Jones and Greenfield (1987) } \\
\text { Ibeas and Jimenez (1997) } \\
\text { Nagodawithana and Steinkraus (1976) } \\
\text { Pampulha and Loureiro-Dias (1989) }\end{array}$ \\
\hline Osmotic & $\begin{array}{l}\text { High accumulation of glycerol } \\
\text { Accumulation of ethanol } \\
\text { Disruption of actin cytoskeleton } \\
\text { Disruption of MAP kinase cascade } \\
\text { Reduction of cell viability }\end{array}$ & $\begin{array}{l}\text { Hohmann (2002) } \\
\text { D'Amore et al. (1988) } \\
\text { Chowdhury et al. (1992) }\end{array}$ \\
\hline Physicochemical (temperature and pH) & $\begin{array}{l}\text { Augmentation of detrimental effects of toxic compounds } \\
\text { Modification of the protein functional structure } \\
\text { Reduction of enzymatic and metabolic activities } \\
\text { Reduction of the cell growth }\end{array}$ & Piper (1993), Kültz (2005) \\
\hline
\end{tabular}

acid anions, protons, and furfural out of the cell, as well as for reactive oxygen species formed during furfural assimilation. The growth-inhibitory effects by potential lignocellulose-derived inhibitors, including phenols [lignin, vanillin, 4-hydroxybenzaldehyde (4-HB), and syringaldehyde], furans (furfural and 5-hydroxymethyl-2-furaldehyde), and organic acids (levulinic, formic, and acetic) on the growth and ethanol production were investigated. From these, phenols and furans exhibited potent inhibitory effects at a concentration of $1 \mathrm{~g} \mathrm{~L}^{-1}$, while organic acids had insignificant impacts at concentrations of up to $2 \mathrm{~g} \mathrm{~L}^{-1}$.

Phenolic compounds released from the hydrolysis of lignin are poorly soluble in aqueous solutions and they can be incorporated into cellular membranes where their partition is higher (Heipieper et al., 1994). Here, phenolic compounds mainly interfere with proteins function and trigger changes in the protein to lipid ratio (Keweloh et al., 1990). Hence, these compounds affect cellular functions like sorting and signaling, as well as cause membrane swelling. Among the 13 tested phenolic compounds, the 4-hydroxy-3-methoxycinnamaldehyde is the most toxic (Adeboye et al., 2014). This, vanillin and catechol are major constituents of syrups from pretreated lignocellulose (Ando, 1966; Palmqvist and Hahn-Hägerdal, 2000b). It is also abundant in hydrolyzates of hardwood, which is toxic at concentration of $1 \mathrm{~g} \mathrm{~L}^{-1}$, reducing $30 \%$ of ethanol yield (Ando et al., 1986). The toxicity of phenolics is very variable as it depends on the functional groups (Ando et al., 1986; Jonsson et al., 2013; Adeboye et al., 2014); more methoxy groups are related to high hydrophobicity and toxicity (Klinke et al., 2004). S. cerevisiae can assimilate many of phenolics which can be part of the detoxification process occurring during fermentation (Mills et al., 1971; Delgenes et al., 1996; Larsson et al., 2000).

\section{Inhibitory Effects of High Ethanol Concentrations}

One of the main advantages of $S$. cerevisiae for ethanol production is the high tolerance that this yeast shows respect to other microorganisms. For example, whereas Escherichia coli and Zymomonas mobilis have maximum tolerances around 60-127 g L L (Lee et al., 1980; Yomano et al., 1998), S. cerevisiae can tolerate ethanol concentrations up to between 115 and $200 \mathrm{~g} \mathrm{~L}^{-1}$ (Luong, 1985). However, ethanol concentrations higher than $150 \mathrm{~g} \mathrm{~L}^{-1}$ can be required to reduce costs in downstream operations. High concentrations of alcohols like ethanol and butanol impaired cellular wall permeability disrupting sorting and signaling functions, as well as provoked an increase in cell size which caused a cell cycle delay (Jones and Greenfield, 1987; Kubota et al., 2004) (Table 1). This correlates with a dispersion of the F-actin cytoskeleton, which is probably regulated by the protein kinase SWE1, which regulates the G2/M transition, since its mutations abolish this phenotype (Kubota et al., 2004). Ethanol also induces petite mutants without mitochondrial DNA (the rho ${ }^{0}$ mutants) and changes in mitochondrial genome (Ibeas and Jimenez, 1997; Chi and Arneborg, 1999). In combination with high temperature, ethanol exacerbates inactivation of some enzymes, for example, the alcohol dehydrogenase (ADH) and the 
hexokinase (Augustin et al., 1965; Nagodawithana and Steinkraus, 1976; Chen and Jin, 2006). The uptake of alanine, proton efflux, and fermentation rates can decrease when cells are exposed to 2M of ethanol (Mishra and Prasad, 1989). Disruption of proton efflux also impairs acid resistance (Brown and Oliver, 1982; Sá-Correia and Van Uden, 1983; Gao and Fleet, 1988; Pampulha and Loureiro-Dias, 1989; Aguilera et al., 2006), since this affects proton outtake for regulation of internal $\mathrm{pH}$. Interestingly, the activity of $\beta$-glucosidase, a cellulosic enzyme used in saccharification, increased with increasing ethanol concentrations from 1 to $9 \%(\mathrm{v} / \mathrm{v})$ (Chen and Jin, 2006). Since cellular wall is the key ethanol target, yeast changes lipid composition, incrementing the proportion of polyunsaturated fatty acids (FAs), ergosterol, and phosphatidylcholine (Mishra and Prasad, 1989; Kajiwara et al., 1996; Chi and Arneborg, 1999). This response is also observed in thermal stress. Eventually, moderate ethanol concentrations also reduce water activity with consequences in metabolic activity (Hallsworth, 1998).

\section{Inhibitory Effects of High Osmolarity}

High gravity fermentations are required for economic considerations. Glucose concentrations superior to $300 \mathrm{~g} \mathrm{~L}^{-1}$ are needed to reach ethanol titers higher than $150 \mathrm{~g} \mathrm{~L}^{-1}$. Thus, the osmolarity of a hydrolyzate can be of 20-200 $\mathrm{g} \mathrm{L}^{-1}$ of salt (0.6-8.6 Osm) (Olsson and Hahn-Hägerdal, 1993). S. cerevisiae can resist 4 Osm, which is much higher compared with $Z$. mobilis, which resists until 1.2 Osm. After being exposed to high osmolarity, yeast cells accumulated high amounts of glycerol which serves as an osmolyte (Hohmann, 2002). Osmotic shock disrupts actin cytoskeleton and invaginations appear affecting the conformation of actin bundles that disturbs MAP kinase cascade, which regulates cell cycle (Chowdhury et al., 1992). This also causes water to flow out of the cell, increasing the concentration of cellular components, including ion concentrations that can serve as a sensor for cellular signaling pathways (Hohmann, 2002). Under osmotic pressure, the excretion of ethanol and glycerol is impaired, leading the accumulation of intracellular ethanol and a decrease in cell viability (Panchal and Stewart, 1980; D’Amore et al., 1988). It seems that membrane fluidity is less prone to be affected by high osmolarity since medium $\mathrm{pH}$ does not have a significant effect on yeast growth at high glucose concentration, but only on ethanol accumulation (Narendranath and Power, 2005).

\section{Inhibitory Effects of High Temperature}

Temperature pervasively practically affects all cellular macromolecules and metabolic functions (Table 1). Increasing temperature from $25-28^{\circ} \mathrm{C}$ to $40^{\circ} \mathrm{C}$ caused a substantial reduction of protein synthesis (Lindquist, 1981; Hottiger et al., 1987), which is accompanied by increasing trehalose accumulation (Hottiger et al., 1987; Neves and Francois, 1992). Both responses are essential to acquire thermotolerance (De Virgilio et al., 1994; Singer and Lindquist, 1998), since null mutants in the trehalose synthase (TSL1) are more sensible to thermal stress (De Virgilio et al., 1994) and significantly decrease heat-shock genes transcription (Hazell et al., 1995), while cells carrying CYR1-2 mutation produce trehalose constitutively, and are significantly more tolerant than the wild type (Hottiger et al., 1989). There is also evidence that trehalose catabolism is needed to acquire thermotolerance and recovering of cellular homeostasis from thermal shock upon temperature upshift from 30 to $40^{\circ} \mathrm{C}$ (Nwaka et al., 1994, 1995). This is evidenced by the recovery of protein production and bud formation after starting trehalose degradation (Hottiger et al., 1987). Trehalose accumulates simultaneously with a reduction of glycolytic rates, albeit intracellular glucose concentrations remain constant (Neves and Francois, 1992). Decreasing of glycolytic rates corresponded to lower activity of the Ras/ cAMP pathway upon thermal shock, which favored trehalose synthesis in detriment of glucose catabolism and cells growth (Shin et al., 1987; Neves and Francois, 1992; Piper, 1993; Tokiwa et al., 1994). After recovering homeostasis, cells increase Ras/ cAMP pathway activity and glycolytic fluxes (Piper, 1993). Both circumstances seem to regulate cyclins activity (CLN1, CLN2, and CLN3) and transcription of CLN3, which are required for cell cycle progression at the START point in G1 phase (Tokiwa et al., 1994; Shi and Tu, 2013), following bud formation. It was recently shown that accumulation of acetyl-CoA, a central metabolite from glucose catabolism, triggers histone acetylation and transcription of CLN3 (Shi and Tu, 2013).

During the acquisition of thermotolerance, yeast cells also change the lipid composition of cellular membrane. Temperature increment caused the increase of saturations and length of FAs as well as a reduction of FA composition in membranes (Suutari et al., 1990, 1997). The synthesis of long-chain bases (LCBs), which are important for membrane fluidity and dynamics, and with possible role in the regulation of signal transduction pathways, also increased (Dickson et al., 1997; Jenkins et al., 1997). Changes in the synthesis of these lipids and some sterols upon temperature increase suggest that pathways supporting signaling networks of the cell wall integrity are involved in heat-shock response (Kamada et al., 1995; Verna et al., 1997; Imazu and Sakurai, 2005). Overexpression of genes coding for antioxidants and enzymes involved in carbon metabolism mediated by the stress-responsive transcription factors (TFs) MSN2 and MSN4, but the Ras/cAMP/PKA signaling pathway cAMP had a negative effect on the induction of the MSN2/MSN4 regulon (Boy-Marcotte et al., 1999; Imazu and Sakurai, 2005). Hence, the former could mainly occur in the precondition effect of trehalose accumulation.

Collectively, these results suggest a toxicity model in which inhibitory conditions associated with ethanol production processes mainly affect cellular membrane concomitant with exchange reactions between the intracellular and extracellular environment, e.g., protons/ions exchange. Accumulation of toxic chemicals through the pretreatment and fermentation operations eventually exacerbates energy requirements and the cell's effort to maintain gradients and to continue the excretion of toxic chemicals. Although mild pretreatment operations or incorporation of detoxification processes reduce the concentration of toxic compounds, such options have to be carefully considered as it may increase the costs and energy consumption. Cellular gradients can also be maintained by increasing medium $\mathrm{pH}$ or supplementing with specific salts. Adaptation of the yeast to process conditions through heritable modifications is, however, the 


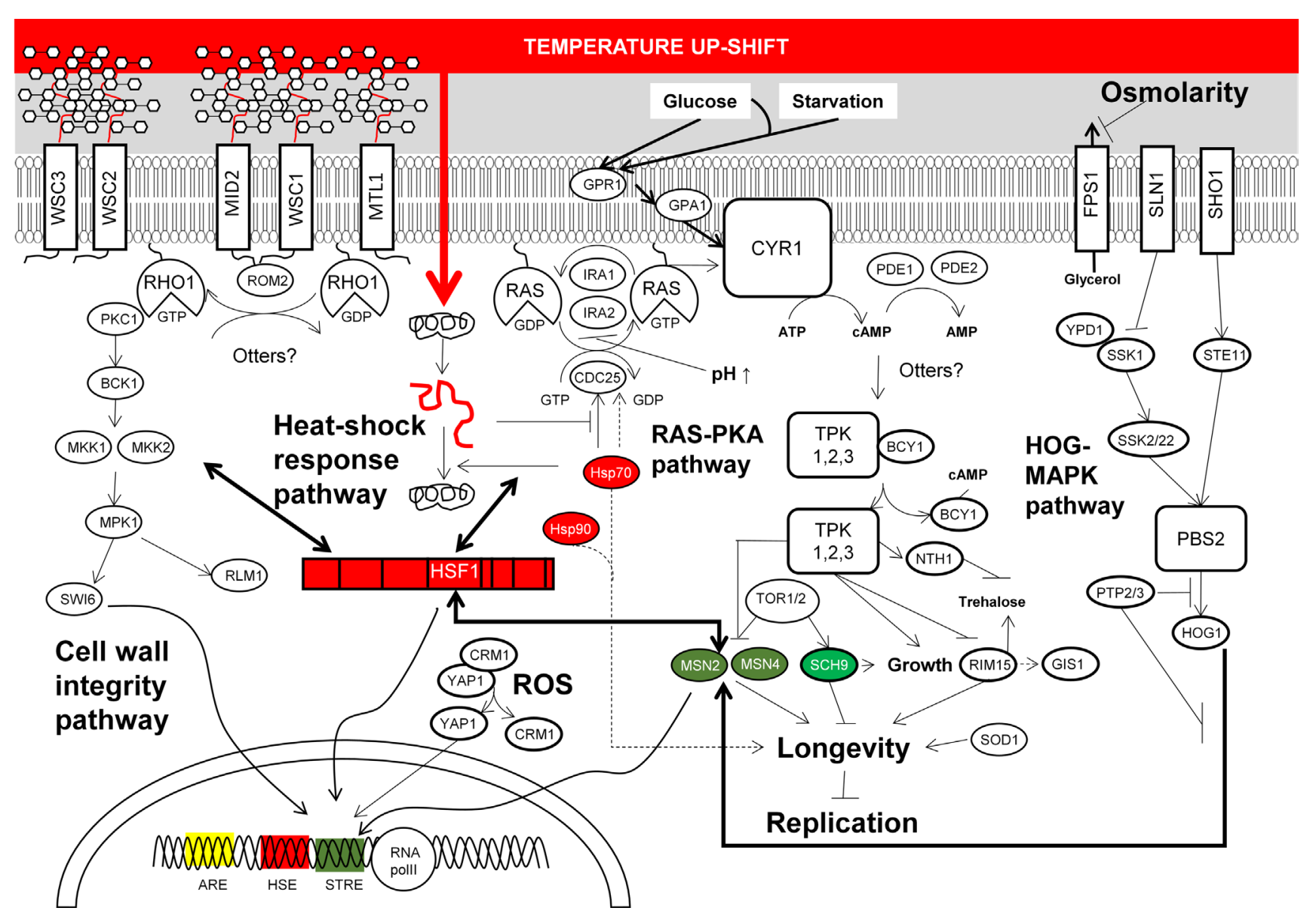

FIGURE 2 | Summarized molecular responses of S. cerevisiae upon exposition to chemical and physical stresses discussed in the main text. This figure condenses the complexity of yeast stress responses upon exposition to high temperature, elevated osmolarity, and low pH. Most of these responses are also triggered upon exposition to toxic chemicals referred to in the main text. The signaling networks from membrane sensors to transcription factors which end with the reconfiguration of transcriptional programs according to stress, and the cross-talk between cellular stress responses are also depicted.

ideal solution, and for this, it is necessary to understand the basic molecular mechanisms underlying the stress response in yeast.

\section{THE CELLULAR STRESS RESPONSE IN YEAST}

Organisms have developed strategies to mount stress responses to recover the constancy of internal state (homeostasis) upon being exposed to environmental changes (Tagkopoulos et al., 2008; Mitchell et al., 2009). These responses are associated to damage in cellular macromolecules and/or redox potentials which disrupt cellular functions (Kültz, 2005; Gibney et al., 2013). Thus, the CSR is universal and have a define set of targeted cellular functions including cell cycle control, protein chaperoning and repair, DNA and chromatin stabilization and repair, cellular membrane stabilization and repair, removal of damaged proteins, and some aspects of metabolism (Kültz, 2005). This assumption raised from the analysis of around 300 highly conserved proteins among different organisms including human, yeast, eubacteria, and archaea, from which more than 44 proteins change their abundance upon stress exposition (Kültz, 2003). Here, it has been pointed out, based on recent results, that most of the inhibitory mechanisms target cellular membrane, redox potentials, and exchange reactions functions.

The results from transcriptomic and proteomic analyses altogether suggest that CSRs in S. cerevisiae overlap at specific stress conditions, whereas some responses are stress specific (Figure 2). Remarkably, this flexibility allows the coordination of stress responses according to a serial of ordered events, which are naturally organized according to its habitat. For example, yeast mounts a stress response to heat, which also serves to tolerate the stress imposed by ethanol and an oxidative environment. This could be a consequence of the domestication of yeast as these stresses appear in this order during the wine production processes (Mitchell et al., 2009). Yeast also triggers a general stress response to survive exposure to several different types of stress. Thus, when S. cerevisiae is exposed to environmental perturbations including temperature increase, nutrient depletion, addition of oxygen peroxide, starvation and stationary phase, 
DNA damaging agents, and hyperosmotic stress among others, a set of around 900 genes showed similar changes in their expression (Gasch et al., 2000). Functional analysis of these genes showed similar targeted functions than those found in proteome analysis (Kültz, 2003, 2005). Differentially expressed genes include those encoding for proteins involved in the RAS-cAMP signaling pathway, which regulate cell metabolism and cell cycle progression in response to nutrient availability (Broach, 1991; Gasch and Werner-Washburne, 2002). Simultaneously, transcription of genes involved in the CSR is also modified by the action of a set of TFs including MSN2/4, YAP1, HSF1, RLM1, and SWI6. Activation of these TFs occurs through phosphorylation cascades triggered by structural changes in proteins located in the cellular membrane; this seems to be the major target for stress agents and the origin of signaling pathways for response to stress (Figure 2).

Reprograming of gene expression in yeast is mainly governed by the general stress response TFs MSN2 and/or MSN4 targeting around 180 genes in response to thermal stress and oxygen peroxide (Gasch et al., 2000). MSN2/MNS4 also induces similar stress responses when yeast cells are exposed to other stresses, suggesting that these TFs induce a general response to various environmental changes (Causton et al., 2001). With regard to the cellular response to oxidative stress, the yeast basic leucine zipper (bZIP) TF YAP1 is mainly in charge of regulating the expression of genes associated to this stress (Temple et al., 2005), as well as in response to xenobiotic insults, including drugs and heavy metals (Lushchak, 2011). Remarkably, transcription of some genes targeted by oxidative stress is also activated by TFs MSN2/MSN4 in response to heat-shock (Gasch et al., 2000). Nonetheless, this response is mainly controlled by the heatshock TF HSF1, which directs the expression of around 150 genes (Hahn et al., 2004). This TF also triggers gene expression changes upon starvation (Hahn and Thiele, 2004), as well as controls the expression of genes associated to life span extension (Shama et al., 1998). Furthermore, it regulates cellular wall remodeling in response to thermal and oxidative stresses (Imazu and Sakurai, 2005; Yamamoto et al., 2007). Some other relevant aspects of particular regulation of CSRs to stressors found in ethanol production processes are given below.

\section{Yeast Responses to Inhibitory Compounds}

Metabolic and molecular responses of yeast exposition to inhibitory compounds, such as furfural and HMF, caused changes in expression of around 886 genes (Ask et al., 2013a). Functional examination of proteomic and transcriptomic analyses showed that genes involved in redox balance, oxidative and salt stress as well as the TFs, MSN2/MSN4, YAP1, and HSF1 were mostly involved in stress responses and specifically, overexpression of YAP1 and MSN2 were related to the increase of yeast tolerance to furfural and HMF (Lin et al., 2009; Sasano et al., 2012). Activity of the MAPK signaling pathway of the yeast response to cell wall integrity was also found to increase yeast tolerance to HMF (Larsson et al., 1999). In agreement with the transcriptional analysis in reference (Dickson et al., 1997), proteomic analysis also showed that redox and energy metabolism are significantly targeted by the stress response in yeast exposed to hydrolyzates containing furans, acids, and/or phenolics (Lin et al., 2009; Lv et al., 2014). In the last study, the authors observed differential expression of around 200 genes, a number similar to the 103 and 227 differentially expressed genes observed from yeast exposition to furfural and acetate, respectively (Li and Yuan, 2010). In this study, it was found that tolerance to furfural also required the overexpression of genes involved in the oxidative stress response, such as SRX1, CTA1, and GRX5 as well as the HSP78, which encodes a mitochondrial chaperone needed for the thermotolerance of this organelle (Heer and Sauer, 2008). In addition, overexpression of some genes related to the lipid and carbohydrate metabolism have been observed within these genes. Interestingly, proteins involved in the TCA cycle were upregulated whereas enzymes of glycerol synthesis were downregulated (Lin et al., 2009). The later results strongly suggest an increment of $\mathrm{NADH}$ demand for furans conversion to alcohols and that this reducing power is generated in TCA cycle.

\section{Yeast Responses to Thermal, Ethanol, and Osmotic Stresses}

In response to heat, $S$. cerevisiae typically shows transcriptional changes in genes encoding metabolic enzymes (e.g., hexokinase, glyceraldehyde-3-phosphate dehydrogenase, glucose6-phosphate dehydrogenase, isocitrate dehydrogenase, and $\mathrm{ADH}$ ), antioxidant enzymes (e.g., thioredoxin 3, thioredoxin reductase, and porin), molecular chaperones and their cofactors (e.g., HSP104, HSP82, HSP60, HSP42, HSP30, HSP26, CPR1, $S T 11$, and ZPR1), and the TFs (e.g., HSF1, MSN2/4, and YAP1), among others (Lindquist, 1986; Piper, 1993; Kim et al., 2013). Most of these genes also change their expression in response to ethanol and high osmolarity (Gasch et al., 2000; Gasch and Werner-Washburne, 2002). However, stress-specific changes in gene expression also responded solely to either YAP1 or MSN2/4 (Gasch et al., 2000). In addition to the implication of TFs in the regulation of gene transcription upon exposure to different types of stress, another intriguing fact is that the dissagregase protein HSP104 and the negative regulator of the $\mathrm{H}(+)$-ATPase, the HSP30 are overexpressed upon exposition to ethanol, heat, and high osmolarity (Sanchez et al., 1992; Piper et al., 1997; Kültz, 2005). These proteins are implicated in the recovery of aggregated proteins and prevent the cells from excessive energy consumption.

Cellular signaling networks of growth and stress response are antagonist. The RAS-PKA pathway, which regulates yeast proliferation in response to nutritional sensing, negatively regulates the activity of the stress-responsive elements (STRE) and the heat-shock elements (HSE) targeted by both RIM15 and MSN2/4, and HSF1 and MSN2/4, respectively (Roosen et al., 2005). Thus, high activity of the RAS-PKA pathway caused by deletion of the $B C Y 1$ is in detriment of stress responses, whereas deletion of RAS2 increased yeast resistance to various stresses except high temperature and osmolarity (Ruis and Schüller, 1995) - this is due to the fact that trehalose metabolism is regulated by NTH1, which is probably activated by the RAS-PKA pathway. High activity of this pathway reduces RIM15 activity, which controls the entry into the G0 phase of cell cycle in response to glucose limitation at the diauxic shift. Its regulon includes gene clusters implicated in 
the adaptation to respiratory growth, including oxidative stress genes (Cameroni et al., 2004). TFs RIM15, GIS1, and MSN2/4 exerts control on genes required for adaptation to oxidative and thermal stress (Cameroni et al., 2004). High RAS-PKA activity favors the activity of SCH9 kinase, which regulates ribosome biogenesis and translation initiation. This is a major target of TORC1 phosphorylation cascade, transiently reduced upon application of osmotic, oxidative, or thermal stress (Urban et al., 2007). Under favorable conditions, TORC1 promotes growth and antagonizes stress response programs (De Virgilio et al., 1994; Jacinto and Hall, 2003). Thus, TORC1 activity is reduced upon stress apparently by its sequestration in granules (Takahara and Maeda, 2012).

The RAS-PKA pathway also connects with the cell wall damage response. PCK1 and the upstream protein elements ROM2 and MTL1 of the PKC1-MAPK cell integrity pathway are needed for actin organization, and required for cellular responses to oxidative, osmotic, and heat stresses (Kamada et al., 1995; Vilella et al., 2005). More evidences on this fact were provided by two different research groups which discovered that the sensitivity to high osmolarity in the HOG-MAPK pathway mutants was reduced at elevated temperature, suggesting that the activation of the cell wall integrity pathway is mainly due to increased temperatures (Alonso-Monge et al., 2001; Wojda et al., 2003). These two pathways and the SVG pathway ensure a proper response of cell wall integrity. The latter is activated by the SHO1 sensor, which also regulates HOG signaling (Figure 2). Furthermore, it was found that membrane sensors WSC1, WSC2, and WSC3 restored the thermo-sensible phenotype of RAS1 mutants - WSC triple mutants did not growth at $37^{\circ} \mathrm{C}$ (Verna et al., 1997), which is another evidence for the connection between RAS-PKA signaling cascade and the cell integrity pathway. Signal transduction of this pathway begins with the cellular membrane proteins WCS1-3, MID2, and MTL1, among others (Rodicio and Heinisch, 2010). Finalizing with the phosphorylation of the TF SWI6 leading its localization into the nucleus required for the unfolded protein response (Scrimale et al., 2009).

Thermal stress also has an important effect on the metabolic responses - e.g., glucose and oxygen consumption rates and biomass yields. In nitrogen-limited chemostats, glucose consumption rate increased up to 1.8 times at $38^{\circ} \mathrm{C}$ compared to $30^{\circ} \mathrm{C}$ (Postmus et al., 2008). Besides ethanol production rate increased 1.7 times, its yield decreased 0.6 times. Furthermore, in the cultivations at $38^{\circ} \mathrm{C}$, glycerol was accumulated at $1.3 \mathrm{mmol} \mathrm{g}_{\mathrm{DCW}}{ }^{-1} \mathrm{~h}^{-1}$ but no accumulation was observed at $30^{\circ} \mathrm{C}$ (Postmus et al., 2012). Despite oxygen uptake rate increase 1.1 times at high temperature, respiratory quotients (RQs) of 2.6 and 3.8 were calculated for the fermentations at low and high temperatures, respectively (Postmus et al., 2012). In the same work, a drastic drop of biomass yield was observed in cultivations grown at high temperature $\left(38^{\circ} \mathrm{C}\right)$ as compared to the cultures developed at low temperature (Postmus et al., 2008). This behavior correlated with an increased flux of glycerol and ethanol at $38^{\circ} \mathrm{C}-$ these were not observed at $30^{\circ} \mathrm{C}$. In both cases, oxygen consumption rate slightly increased suggesting that reducing power produced in glycolysis is balanced by glycerol production and interrupted electron transport chain.
These results altogether show the complexity of cell stress responses and the difficulties for generating complex thermotolerant phenotypes. Therefore, selection of thermotolerant microorganisms from harsh environments similar to those found in ethanol production process is still a recurrent option. However, these microorganisms will eventually be useless when process conditions change - this will be especially true in the foundation of lignocellulosic biorefineries. Thus, a rational cell design based on knowledge of cell responses will enable the design of generic cell factories that can be used in several different processes. One must be aware that there would be physical components that limit biological augmentation. In this case, synthetic biology approaches (Alper and Stephanopoulos, 2009) and utilization of additional operations to remove toxic molecules can be of interest. In the last section, we review the current strategies for rational improving of yeast tolerance to ethanol production processes.

\section{IMPROVING YEAST TOLERANCE TO INHIBITORY CONDITIONS FOUND IN ETHANOL PRODUCTION PROCESS}

Some of the methods for increasing yeast tolerance to harmful conditions found in ethanol production processes are summarized in Table 2. These methods include the adaptive laboratory evolution (ALE), which is performed by serial dilution of microbial population in fresh media, maintaining or increasing the intensity of the stress (Elena and Lenski, 2003). The main advantage of this method is that increased fitness can be followed during the evolution, and populations can be screened for a strain with a useful phenotype - e.g., improved growth or increased glucose consumption. When combined with partial or complete genome sequence of isolated strains/populations, as well as genome level analysis of gene expression and metabolic fluxes, this procedure is very powerful to get basic knowledge about cell strategies that arise with the better performance (Hong et al., 2011; Caspeta et al., 2014b).

Evolution of linear DNA fragments upon recombination of blocks of sequences rather than point mutagenesis alone has shown to be more important during evolution. The DNA shuffling technology is a procedure for rapid propagation of beneficial mutations in a direct evolution experiment (Stemmer, 1994). This is based on repeated cycles of point mutagenesis, recombination, and selection allowing molecular evolution of complex sequences, through increasing the size of DNA library (Zhang et al., 2002). In combination with cellular mating, this technology has led the generation of cells resistance to ethanol production processes (Pinel et al., 2011).

Despite changes on expression of a single gene have given good results in generating the tolerant phenotype (Caspeta et al., 2014b; Lam et al., 2014), this does not typically occurs since the tolerance to stressors requires changes of expression for thousand genes (see The Cellular Stress Response in Yeast). Therefore, the engineering of global transcription machinery has been developed to generate TFs that may lead with a proper reprograming of gene transcription network, which arises with the desired tolerant 
TABLE 2 | Some examples of the strategies to improve yeast stress tolerance to inhibitory conditions during the conversion of lignocellulosic biomass to ethanol.

\begin{tabular}{ll} 
Molecular strategies & Specific cases \\
\hline Adaptive evolution & The industrial S. cerevisiae ethanol red was subjected to a long-term adaptive laboratory evolution. The \\
& resultant strain was able to grow and produce ethanol using non-detoxified spruce hydrolyzates \\
& Using adaptive laboratory evolution/visualizing evolution at real time, seven strains were isolated due to \\
their improved tolerance to lignocellulosic biomass hydrolyzates & Gorwa-Grauslund (2013) \\
& $\begin{array}{l}\text { S. cerevisiae strain CENPK113-7D was evolved in laboratory and seven thermotolerant strains were } \\
\text { isolated. These strains were able to grow at } 40^{\circ} \mathrm{C} \text { under fully aerobic conditions with improved kinetic }\end{array}$
\end{tabular}

Reprograming gene expression

Direct evolution - DNA shuffling technology

Random mutations (by chemical agents or UV) Heterologous expression isolated. These strains were able to grow at $40^{\circ} \mathrm{C}$ under fully aerobic conditions with improved kinetic parameters as compared to the parental strain

Mutagenesis of the transcription factor SPT15 allows to increase osmotic and ethanol tolerance, improving ethanol production

The strain S. cerevisiae R57 was isolated after five rounds of DNA evolution by DNA shuffling. It was able to survive, grow, and produce ethanol using a substrate, hardwood spent sulfite liquor. This strain also increased its viability in presence of salt, peroxide, acetic acid, and sorbitol

Three S. cerevisiae strains with improved tolerance to vanillin, furfural, and acetic acid were generated by random mutagenesis with ethyl methane sulfonate coupled to an adaptive laboratory evolution strategy

The laccase I from Trametes sp. was cloned in yeast. The laccase-1 displaying yeast has oxidation activity and was effective during pretreatment for ethanol fermentation
Alper et al. (2006)

Pinel et al. (2011, 2015)

Shen et al. (2014) phenotype (Alper and Stephanopoulos, 2009). This method consists on the mutagenesis of TFs acting with a desired promotor sequences - e.g., the TATA-binding, and the selection of dominant mutations conferring the desired tolerant phenotype.

Random mutagenesis with chemical or physical agents, for example, the dimethyl sulfate (DMS) and UV radiation, has been used for long time to generate populations with a set of mutations from which the useful ones are selected from experiments with the desired environmental pressure. This method has been used in combination with cellular shorting procedures to analyze thousands of phenotypes and came up with the most desired one (Huang et al., 2015). Despite this method being useful for generating tolerant phenotypes, it rarely permits the analysis of mutations that arise with the desired phenotype.

\section{Increasing Ethanol Tolerance}

Despite $S$. cerevisiae showing high ethanol tolerance, there have been many efforts to enhance this trait and generate strains tolerant to higher concentrations; here are some of the recent advances. Comparison of gene expression among tolerant and non-tolerant strains has served to recognize target genes involved in ethanol tolerance. Some genes involved in this feature are the global TF MSN2, some genes of the cAMP-PKA signaling pathway, genes related to the cellular wall integrity, and some genes encoding enzymes of lipids and carbohydrates metabolism (Lewis et al., 2010). It was shown recently that the manipulation of ions transport systems can also improve ethanol tolerance. For instance, changing potassium ion and proton electrochemical forces can improve yeast tolerance to ethanol (Lam et al., 2014). Overexpression of the TRK1 gene, a member of the potassium transport system, and the $\mathrm{H}(+)$-ATPase gene, PMA1, in laboratory strains increased ethanol production by around 30\% respect to the laboratory strain S288C and by $10 \%$ compared to industrial strains (Lam et al., 2014). In contrast to those findings, thermally evolved S. cerevisiae strains, which showed slight increase of ethanol tolerance, did not overexpress PMA1 (Caspeta et al., 2014b). The negative regulator of the $\mathrm{H}(+)$-ATPase pump, the gene HSP30, however, increased upon thermal stress (Piper et al., 1997; Meena et al., 2011), suggesting that thermal adaptation may optimize ATP usage for proton excretion, thus decreasing energy for maintenance. Thereafter, electrical potential and proton fluxes can decrease free energy of ATP hydrolysis for proton export (Maris et al., 2004), enhancing the resistance to alcohols (Lam et al., 2014).

Transcription reprograming of yeast gene expression using the global transcription machinery engineering approach leaded with higher ethanol resistance. The mutagenesis of the TF SPT15 allowed the selection of the SPT15-300 TF with a mutation in the phenylalanine ( $\mathrm{Phe}^{177} \mathrm{Ser}$ ) as the dominant mutation which provided increased tolerance to elevated concentrations of glucose and ethanol, as well as improved ethanol production (Alper et al., 2006).

\section{Increasing Tolerance to Toxic Compounds}

Adaptive laboratory evolution has been successfully used for selection of yeast strains tolerant to lignocellulose hydrolyzates containing furfural, HMF, and acetate (Liu et al., 2005; Keating et al., 2006; Heer and Sauer, 2008). Evolution of yeast populations in synthetic medium containing $3 \mathrm{mM}$ furfural resulted in the selection of tolerant strains after 300 generations (Heer and Sauer, 2008). These strains reduced the lag-phase of growth suggesting that furfural conversion to its alcohol is the main factor for improving the tolerance. In agreement with this, the evolution of the industrial yeast strain TMB3400 in synthetic mixtures of sugars supplemented with furfural, HMF, and acetic acid showed faster consumption of these inhibitors (Keating et al., 2006). Furthermore, the conversion of furfural to furfuryl alcohol at significantly higher rates was the solution of evolved S. cerevisiae and Pichia pastoris strains to tolerate these chemicals (Liu et al., 2005). These results suggest that detoxification of furfural and 
HMF can be carried out in place with yeast strains having higher ability to convert such toxic molecules.

Evolution of the industrial strain ethanol red of $S$. cerevisiae in non-detoxified spruce hydrolyzate in combination to high temperature $\left(39^{\circ} \mathrm{C}\right)$ resulted in the selection of strains capable to convert spruce hydrolyzates into ethanol with high efficiency (Wallace-Salinas and Gorwa-Grauslund, 2013). Contrary to the resistance in evolved strains selected with furfural and HMF alone, the superior phenotype of the evolved ethanol red strains did not rely on higher reductase activities for furfural conversion, but rather on a higher thermotolerance. Different results were also observed in tolerant yeast strains obtained from evolutionary engineering using genome-shuffling technology based on largescale population with cross-mating to generate tolerance to spent sulfite liquor (SSL) (Pinel et al., 2011). These strains were also more tolerant to higher osmolarities, elevated ethanol concentrations, and higher amounts of acetic acid than the parental strain.

Studies based on the change in gene expression using microarrays have led to the identification of redox balance and energy state of the cells as the major drivers to generate tolerance to furfural and HMF (Petersson et al., 2006; Ask et al., 2013a). From the 15 reductases which overexpression were found to improve tolerance, the overexpression of three candidate genes raised with the recognition of $A D H 6$ as one of the major contributors for tolerance to HMF in aerobic and anaerobic conditions (Petersson et al., 2006). It has been also demonstrated that tolerance to furfural can be increased by the overexpression of $A D H 7$, the ORF YKL071W, and ARI1 genes, which encode are reductases involved in furfural reduction (Heer et al., 2009; Sehnem et al., 2013). Combining the overexpression of the ADH ADH1 with the transaldolase $T A L 1$ in recombinant xylose-fermenting $S$. cerevisiae improves ethanol production from lignocellulosic hydrolyzates. Most of the tolerant strains generated by these means increase furfural and HMF conversion to their less toxic alcohols. This strategy has been also effective in E. coli, in which the overexpression of reductases YGHD and $D K G A$, having NADPH-dependent furfural reductase activity, increases furfural tolerance (Miller et al., 2009).

Besides the overexpression of TAL1, the overexpression of some genes of the pentose phosphate pathway also increases yeast tolerance to furfural. Among them, the overexpression of $Z W F 1, G N D 1$, or RPE1 induced tolerance to furfural at concentrations that are normally toxic in the wild-type strain (Gorsich et al., 2006). These results were similar to those observed when the xylose reductase and xylitol dehydrogenase from $P$. pastoris were overexpressed in combination with overexpression of the endogenous xylulose kinase of $S$. cerevisiae (Almeida et al., 2008). On the other hand, the overexpression of YAP1 activated the transcription of catalases genes CTA1 and CTT1, enhancing the tolerance to furfural but not to HMF (Kim and Hahn, 2013), suggesting that rapid furfural consumption is associated to accumulation to reactive oxygen species.

The evolutionary engineering through genome-shuffling technology was used to increase yeast tolerance to hardwood SSL (Pinel et al., 2011). Using RNA-seq gene expression analysis, these authors found that the products of the genes $U B P 7$ and ART5 (both related to ubiquitin-mediated proteolysis), NRG1 (a stress-response transcriptional repressor), and GDH1 (a NADPHdependent glutamate dehydrogenase), play an important role in the tolerance to these hydrolyzates (Pinel et al., 2015). The genome-shuffling technology method was also used to increase tolerance to a combination of heat, acetic acid, and furfural stresses (Lu et al., 2012). The resulted strains showed tolerance to $0.55 \%(\mathrm{v} / \mathrm{v})$ acetic acid and $0.3 \%(\mathrm{v} / \mathrm{v})$ furfural at $40^{\circ} \mathrm{C}$.

Tolerance to phenolics can be tackled by the expression of extracellular heterologous laccases (Lee et al., 2012). This trait can be also enhanced by heterologous expression of the gene encoding the phenyl acrylic-acid decarboxylase (PSP1), which catalyzes the decarboxylation of aromatic carboxylic acids into the corresponding vinyl derivatives (Richard et al., 2015). Overexpression of multidrug efflux pump genes ATR1 and FLR1, and the TF YAP1 also resulted in yeast resistance to coniferyl aldehyde and HMF (Alriksson et al., 2010). Tolerance to vanillin and $39^{\circ} \mathrm{C}$ were induced after several rounds of mutagenesis in hydrolyzates containing vanillin (Kumari and Pramanik, 2012). Chemical mutagenesis coupled with ALE using continuous cultivation in $60 \%(\mathrm{v} / \mathrm{v})$ non-detoxified hydrolyzate liquor from steam-pretreated lignocellulose was successfully used to select yeast strains with improved capacity to ferment xylose from lignocellulose hydrolyzates (Smith et al., 2014). Since many of the toxic compounds affect the membrane potential, the addition of spermidine, which synchronize $\mathrm{Ca}^{2+}, \mathrm{Na}^{+}, \mathrm{K}^{+}$, and ATPase has also proven to induce tolerance, after disruption of the spermidine metabolism genes $O A Z 1$ coding for an ornithine decarboxylase (ODC) enzyme and TPO1 coding for the polyamine transport protein (Kim et al., 2015). Changes in ergosterol composition have shown to improve tolerance to vanillin in strains overexpressing the ergosterol synthesis genes ERG28, HMG1, MCR1, ERG5, and ERG7 (Endo et al., 2009).

\section{Increasing Tolerance to High Temperature and Elevated Osmolality}

Adaptive laboratory evolution has been successful for selecting thermotolerant S. cerevisiae strains (Yona et al., 2012; Caspeta et al., 2014b). After an evolution period of 450 generations, thermotolerant yeast populations were isolated from experiments performed at $39^{\circ} \mathrm{C}$ (Yona et al., 2012). These populations showed a duplication in chromosome number III (ChIII) and overexpression of related genes. However, only the overexpression of some genes found in this chromosome including the TF HCM1 and the protease RRT12 reproduced a significant fraction of the thermotolerant phenotype in the parental strain. A similar result was found in thermotolerant yeast strains isolated from ALE experiments to $39.5^{\circ} \mathrm{C}$ (Caspeta et al., 2014b). In this work, a partial duplication of ChIII containing the HCM1 gene was found. Since duplication of ChIII was lost in evolved strains, this suggests that chromosomal duplications are a temporal solution to stress (Yona et al., 2012).

Adaptive laboratory evolution experiments have also used to generate tolerance to high $\mathrm{pH}$, which induced the duplication of chromosome number five (Yona et al., 2012). Remarkably, chromosomal duplications only appear in diploid cells since haploid S. cerevisiae populations showed segmental duplications only. In 
these strains, a nonsense mutation of ERG3 proportionated $80 \%$ of the thermotolerant phenotype (Caspeta et al., 2014b). This result and the fact that ethanol tolerance can be achieved by just one overexpression suggest that complex tolerant phenotypes can be achievable by just one mutation. Remarkably, this mutation changed cellular membrane properties.

Genome-shuffling technology was used to improve yeast performance in high gravity fermentations (Liu et al., 2011). The resulted strains derived from a diploid STE2/STE2 (receptor for alpha-factor pheromone) strain increased tolerance to high osmolarity and elevated ethanol concentrations. This method was also used to generate sexual and asexual populations of $S$. cerevisiae resistant to very high gravity fermentations, elevated temperature, and high glucose concentrations (Hou, 2010). In mutants of the gene GPD2 encoding glycerol 3-phosphate dehydrogenase subjected to three rounds of genome shuffling, a population of strains producing lower amounts of glycerol and improved tolerance to ethanol and high osmolality were able to be selected (Tao et al., 2012). These strains showed changes in FAs composition and higher accumulation of trehalose. A remarkable application of the genome-shuffling technology was the generation of both thermotolerance and ethanol tolerance in the industrial yeast strain SM-3, which were used to ferment syrups with $20 \%$ (w/v) glucose at $45^{\circ} \mathrm{C}$ and resists $9.5 \%$ (w/v) ethanol (Shi et al., 2009).

\section{CONCLUDING REMARKS}

One of the major challenges for economic conversion of lignocellulose to fuel ethanol is to generate robust $S$. cerevisiae strains able to cope with inhibitory conditions while keeping proper catalytic functions for raw material conversion to ethanol. Major inhibitory conditions found in the unit operations required for the conversion processes include the accumulation of toxic chemicals generated during lignocellulose pretreatment and sugar fermentation, the high temperature that accompanied simultaneous saccharification and fermentation, and the very high osmolality and elevated solids loadings at the beginning of the fermentation. Since unification of these unit operations is desirable to reduce production costs and energy utilization, it can be expected that yeast cells will be simultaneously exposed to most of these inhibitory conditions.

\section{REFERENCES}

Adeboye, P. T., Bettiga, M., and Olsson, L. (2014). The chemical nature of phenolic compounds determines their toxicity and induces distinct physiological responses in Saccharomyces cerevisiae in lignocellulose hydrolysates. $A M B$ Express 4, 46-46. doi:10.1186/s13568-014-0046-7

Aguilera, F., Peinado, R. A., Millán, C., Ortega, J. M., and Mauricio, J. C. (2006). Relationship between ethanol tolerance, H+-ATPase activity and the lipid composition of the plasma membrane in different wine yeast strains. Int. J. Food Microbiol. 110, 34-42. doi:10.1016/j.ijfoodmicro.2006.02.002

Allen, S., Clark, W., Mccaffery, J. M., Cai, Z., Lanctot, A., Slininger, P., et al. (2010). Furfural induces reactive oxygen species accumulation and cellular damage in Saccharomyces cerevisiae. Biotechnol. Biofuels 3, 2. doi:10.1186/1754-6834-3-2

Almario, M. P., Reyes, L. H., and Kao, K. C. (2013). Evolutionary engineering of Saccharomyces cerevisiae for enhanced tolerance to hydrolysates of lignocellulosic biomass. Biotechnol. Bioengin. 110, 2616-2623. doi:10.1002/bit.24938
Since cellular macromolecules and metabolism have evolved to sustain optimal growth rates at the prevailed natural conditions, mainly preserving genetic information and proteins/membrane functional structures, the generation of complex tolerant phenotypes for the ethanol industry will be further generated on the bases of the functions targeted by the stressors. The summarized results altogether show that major targets include cellular membrane, redox and ionic potentials, and energy metabolism, as well as protein structure - the latter of apparently minor relevance.

To establish metabolic engineering strategies for increasing yeast tolerance, it is suggested to consider the route and regulation of molecular responses following sensing, signal transduction, signal integration, and execution of cellular functions in response to environmental stresses. Results from systems biology and -omics analyses, as well as from traditional data mining, point out the relevance of the cross-regulation between the routes of yeast responses according to the different types of stress. This is part of the elasticity of cellular stress-signaling network, which is advantageous during evolutionary adaptation and in the generation of resistance to the multiple stresses found in ethanol production process.

In summary, the multiple technologies for the generation of numerous mutations, high-throughput screening, acceleration of cells adaptation and selection, laboratory evolution and engineering of TFs, and the new tools for controlling gene expression are accelerating the accumulation of basic information of CSRs, and the generation of yeast cells with desirable processing characteristics including better performance in the inhibitory conditions found in lignocellulosic ethanol production processes.

\section{ACKNOWLEDGMENTS}

LC thanks the Secretaría de Educación Pública (SEP) which financed his integration into the Autonomous University of Morelos State and covered publication fees through the Programa para el Desarrollo Profesional Docente (PRODEP) (grant no. DSA/103.5/14/10703). TC thanks the National Council of Science (CONACyT) for the postdoctoral scholarship. JN thanks Novo Nordisk Foundation, the Knut och Alice Wallenbergs Stiftelse, and Vetenskapsrådet for the funding received to perform work related to the topics covered in this review.

Almeida, J., Modig, T., Roder, A., Liden, G., and Gorwa-Grauslund, M.-F. (2008). Pichia stipitis xylose reductase helps detoxifying lignocellulosic hydrolysate by reducing 5-hydroxymethyl-furfural (HMF). Biotechnol. Biofuels 1, 12. doi:10.1186/1754-6834-1-12

Alonso-Monge, R., Real, E., Wojda, I., Bebelman, J.-P., Mager, W. H., and Siderius, M. (2001). Hyperosmotic stress response and regulation of cell wall integrity in Saccharomyces cerevisiae share common functional aspects. Mol. Microbiol. 41, 717-730. doi:10.1046/j.1365-2958.2001.02549.x

Alper, H., Moxley, J., Nevoigt, E., Fink, G. R., and Stephanopoulos, G. (2006). Engineering yeast transcription machinery for improved ethanol tolerance and production. Science 314, 1565-1568. doi:10.1126/ science.1131969

Alper, H., and Stephanopoulos, G. (2009). Engineering for biofuels: exploiting innate microbial capacity or importing biosynthetic potential? Nat. Rev. Microbiol. 7, 715-723. doi:10.1038/nrmicro2186

Alriksson, B., Horváth, I. S., and Jönsson, L. J. (2010). Overexpression of Saccharomyces cerevisiae transcription factor and multidrug resistance genes 
conveys enhanced resistance to lignocellulose-derived fermentation inhibitors. Process Biochem. 45, 264-271. doi:10.1016/j.procbio.2009.09.016

Ando, S., Arai, I., Kiyoto, K., and Hanai, S. (1986). Identification of aromatic monomers in steam-exploded poplar and their influences on ethanol fermentation by Saccharomyces cerevisiae. J. Ferment. Technol. 64, 567-570. doi:10.1016/0385-6380(86)90084-1

Ando, T. (1966). A nuclease specific for heat-denatured DNA in isolated from a product of Aspergillus oryzae. Biochim. Biophys. Acta 114, 158-168. doi:10.1016/0005-2787(66)90263-2

Ask, M., Bettiga, M., Duraiswamy, V., and Olsson, L. (2013a). Pulsed addition of HMF and furfural to batch-grown xylose-utilizing Saccharomyces cerevisiae results in different physiological responses in glucose and xylose consumption phase. Biotechnol. Biofuels 6, 181. doi:10.1186/1754-6834-6-181

Ask, M., Bettiga, M., Mapelli, V., and Olsson, L. (2013b). The influence of HMF and furfural on redox-balance and energy-state of xylose-utilizing Saccharomyces cerevisiae. Biotechnol. Biofuels 6, 22. doi:10.1186/1754-6834-6-22

Augustin, H. W., Kopperschläger, G., Steffen, H., and Hofmann, E. (1965). Hexokinase as limiting factor of anaerobic glucose consumption of Saccharomyces carlsbergensis NCYC74. Biochim. Biophys. Acta 110, 437-439. doi:10.1016/S0926-6593(65)80055-8

Ballesteros, I., Ballesteros, M., Cabañas, A., Carrasco, J., Martín, C., Negro, M. J., et al. (1991). Selection of thermotolerant yeasts for simultaneous saccharification and fermentation (SSF) of cellulose to ethanol. Appl. Biochem. Biotechnol. 2, 307-315. doi:10.1007/bf02922610

Banerjee, N., Bhatnagar, R., and Viswanathan, L. (1981). Inhibition of glycolysis by furfural in Saccharomyces cerevisiae. Eur. J. Appl. Microbiol. Biotechnol. 11, 226-228. doi:10.1007/bf00505872

Boy-Marcotte, E., Lagniel, G., Perrot, M., Bussereau, F., Boudsocq, A., Jacquet, M., et al. (1999). The heat shock response in yeast: differential regulations and contributions of the Msn2p/Msn4p and Hsflp regulons. Mol. Microbiol. 33, 274-283. doi:10.1046/j.1365-2958.1999.01467.x

Broach, J. R. (1991). RAS genes in Saccharomyces cerevisiae: signal transduction in search of a pathway. Trends Genet. 7, 28-33. doi:10.1016/0168-9525(91)90018-L

Brown, S., and Oliver, S. (1982). The effect of temperature on the ethanol tolerance of the yeast, Saccharomyces uvarum. Biotechnol. Lett. 4, 269-273. doi:10.1007/ bf00132399

Cameroni, E., Hulo, N., Roosen, J., Winderickx, J., and Virgilio, C. D. (2004). The novel yeast PAS kinase Rim 15 orchestrates $\mathrm{G} 0$-associated antioxidant defense mechanisms. Cell Cycle 3, 460-466. doi:10.4161/cc.3.4.791

Casal, M., Cardoso, H., and Leao, C. (1996). Mechanisms regulating the transport of acetic acid in Saccharomyces cerevisiae. Microbiology 142, 1385-1390. doi:10.1099/13500872-142-6-1385

Caspeta, L., Buijs, N. A. A., and Nielsen, J. (2013). The role of biofuels in the future energy supply. Energy Environ. Sci. 6, 1077-1082. doi:10.1039/c3ee24403b

Caspeta, L., Caro-Bermúdez, M. A., Ponce-Noyola, T., and Martinez, A. (2014a). Enzymatic hydrolysis at high-solids loadings for the conversion of agave bagasse to fuel ethanol. Appl. Energy 113, 277-286. doi:10.1016/j.apenergy.2013.07.036

Caspeta, L., Chen, Y., Ghiaci, P., Feizi, A., Buskov, S., Hallström, B. M., et al. (2014b). Altered sterol composition renders yeast thermotolerant. Science 346, 75-78. doi:10.1126/science.1258137

Caspeta, L., and Nielsen, J. (2013). Economic and environmental impacts of microbial biodiesel. Nat. Biotechnol. 31, 789-793. doi:10.1038/nbt.2683

Causton, H. C., Ren, B., Koh, S. S., Harbison, C. T., Kanin, E., Jennings, E. G., et al. (2001). Remodeling of yeast genome expression in response to environmental changes. Mol. Biol. Cell 12, 323-337. doi:10.1091/mbc.12.2.323

Chen, H., and Jin, S. (2006). Effect of ethanol and yeast on cellulase activity and hydrolysis of crystalline cellulose. Enzyme Microb. Technol. 39, 1430-1432. doi:10.1016/j.enzmictec.2006.03.027

Chi, Z., and Arneborg, N. (1999). Relationship between lipid composition, frequency of ethanol-induced respiratory deficient mutants, and ethanol tolerance in Saccharomyces cerevisiae. J. Appl. Microbiol. 86, 1047-1052. doi:10.1046/j.1365-2672.1999.00793.x

Chowdhury, S., Smith, K. W., and Gustin, M. C. (1992). Osmotic stress and the yeast cytoskeleton: phenotype-specific suppression of an actin mutation. J. Cell Biol. 118, 561-571. doi:10.1083/jcb.118.3.561

D’Amore, T., Panchal, C., Russeil, I., and Stewart, G. (1988). Osmotic pressure effects and intracellular accumulation of ethanol in yeast during fermentation. J. Ind. Microbiol. 2, 365-372. doi:10.1007/bf01569575
De Virgilio, C., Hottiger, T., Dominguez, J., Boller, T., and Wiemken, A. (1994). The role of trehalose synthesis for the acquisition of thermotolerance in yeast. Eur. J. Biochem. 219, 179-186. doi:10.1111/j.1432-1033.1994.tb19928.x

Delgenes, J. P., Moletta, R., and Navarro, J. M. (1996). Effects of lignocellulose degradation products on ethanol fermentations of glucose and xylose by Saccharomycescerevisiae, Zymomonas mobilis, Pichia stipitis, and Candida shehatae. Enzyme Microb. Technol. 19, 220-225. doi:10.1016/0141-0229(95)00237-5

Diaz De Villegas, M. E., Villa, P., Guerra, M., Rodriguez, E., Redondo, D., and Martinez, A. (1992). Conversion of furfural into furfuryl alcohol by Saccharomyces cervisiae 354. Acta Biotechnol. 12, 351-354. doi:10.1002/ abio. 370120420

Dickson, R. C., Nagiec, E. E., Skrzypek, M., Tillman, P., Wells, G. B., and Lester, R. L. (1997). Sphingolipids are potential heat stress signals in Saccharomyces. J. Biol. Chem. 272, 30196-30200. doi:10.1074/jbc.272.48.30196

Edgardo, A., Carolina, P., Manuel, R., Juanita, F., and Baeza, J. (2008). Selection of thermotolerant yeast strains Saccharomyces cerevisiae for bioethanol production. Enzyme Microb. Technol. 43, 120-123. doi:10.1016/j.enzmictec.2008.02.007

Elena, S. F., and Lenski, R. E. (2003). Evolution experiments with microorganisms: the dynamics and genetic bases of adaptation. Nat. Rev. Genet. 4, 457-469. doi: $10.1038 / \operatorname{nrg} 1088$

Endo, A., Nakamura, T., and Shima, J.(2009). Involvement ofergosterolin toleranceto vanillin, a potential inhibitor of bioethanol fermentation, in Saccharomyces cerevisiae. FEMS Microbiol. Lett. 299, 95-99. doi:10.1111/j.1574-6968.2009.01733.x

Field, S., Ryden, P., Wilson, D., James, S., Roberts, I., Richardson, D., et al. (2015). Identification of furfural resistant strains of Saccharomyces cerevisiae and Saccharomyces paradoxus from a collection of environmental and industrial isolates. Biotechnol. Biofuels 8, 33. doi:10.1186/s13068-015-0217-z

Gao, C., and Fleet, G. H. (1988). The effects of temperature and $\mathrm{pH}$ on the ethanol tolerance of the wine yeasts, Saccharomyces cerevisiae, Candida stellata and Kloeckera apiculata. J. Appl. Bacteriol. 65, 405-409. doi:10.111 1/j.1365-2672.1988.tb01909.x

Garay-Arroyo, A., Covarrubias, A. A., Clark, I., Niño, I., Gosset, G., and Martinez, A. (2004). Response to different environmental stress conditions of industrial and laboratory Saccharomyces cerevisiae strains. Appl. Microbiol. Biotechnol. 63, 734-741. doi:10.1007/s00253-003-1414-4

Gasch, A., and Werner-Washburne, M. (2002). The genomics of yeast responses to environmental stress and starvation. Funct. Integr. Genomics 2, 181-192. doi:10.1007/s10142-002-0058-2

Gasch, A. P., Spellman, P. T., Kao, C. M., Carmel-Harel, O., Eisen, M. B., Storz, G., et al. (2000). Genomic expression programs in the response of yeast cells to environmental changes. Mol. Biol. Cell 11, 4241-4257. doi:10.1091/ mbc.11.12.4241

Gibney, P. A., Lu, C., Caudy, A. A., Hess, D. C., and Botstein, D. (2013). Yeast metabolic and signaling genes are required for heat-shock survival and have little overlap with the heat-induced genes. Proc. Natl. Acad. Sci. U.S.A. 110, 4393-4402. doi:10.1073/pnas.1318100110

Gorsich, S. W., Dien, B. S., Nichols, N. N., Slininger, P. J., Liu, Z. L., and Skory, C. D. (2006). Tolerance to furfural-induced stress is associated with pentose phosphate pathway genes ZWF1, GND1, RPE1, and TKL1 in Saccharomyces cerevisiae. Appl. Microbiol. Biotechnol. 71, 339-349. doi:10.1007/s00253-005-0142-3

Haelssig, J. B., Tremblay, A. Y., and Thibault, J. (2008). Technical and economic considerations for various recovery schemes in ethanol production by fermentation. Ind. Eng. Chem. Res. 47, 6185-6191. doi:10.1021/ie0715005

Hahn, J.-S., Hu, Z., Thiele, D. J., and Iyer, V. R. (2004). Genome-wide analysis of the biology of stress responses through heat shock transcription factor. Mol. Cell Biol. 24, 5249-5256. doi:10.1128/mcb.24.12.5249-5256.2004

Hahn, J.-S., and Thiele, D. J. (2004). Activation of the Saccharomyces cerevisiae heat shock transcription factor under glucose starvation conditions by snfl protein kinase. J. Biol. Chem. 279, 5169-5176. doi:10.1074/jbc.M311005200

Hallsworth, J. E. (1998). Ethanol-induced water stress in yeast. J. Ferment. Bioeng. 85, 125-137. doi:10.1016/S0922-338X(97)86756-6

Hazell, B. W., Nevalainen, H., and Attfield, P. V. (1995). Evidence that the Saccharomycescerevisiae CIF1(GGS1/TPS1)genemodulatesheat shock response positively. FEBS Lett. 377, 457-460. doi:10.1016/0014-5793(95)01392-X

Heer, D., Heine, D., and Sauer, U. (2009). Resistance of Saccharomyces cerevisiae to high concentrations of furfural is based on NADPH-dependent reduction by at least two oxireductases. Appl. Environ. Microbiol. 75, 7631-7638. doi:10.1128/ aem.01649-09 
Heer, D., and Sauer, U. (2008). Identification of furfural as a key toxin in lignocellulosic hydrolysates and evolution of a tolerant yeast strain. Microb. Biotechnol. 1, 497-506. doi:10.1111/j.1751-7915.2008.00050.x

Heipieper, H. J., Weber, F. J., Sikkema, J., Keweloh, H., and De Bont, J. A. M. (1994). Mechanisms of resistance of whole cells to toxic organic solvents. Trends Biotechnol. 12, 409-415. doi:10.1016/0167-7799(94)90029-9

Hohmann, S. (2002). Osmotic stress signaling and osmoadaptation in yeasts. Microbiol. Mol. Biol. Rev. 66, 300-372. doi:10.1128/mmbr.66.2.300-372.2002

Holyoak, C. D., Stratford, M., Mcmullin, Z., Cole, M. B., Crimmins, K., Brown, A. J., et al. (1996). Activity of the plasma membrane H(+)-ATPase and optimal glycolytic flux are required for rapid adaptation and growth of Saccharomyces cerevisiae in the presence of the weak-acid preservative sorbic acid. Appl. Environ. Microbiol. 62, 3158-3164.

Hong, K.-K., Vongsangnak, W., Vemuri, G. N., and Nielsen, J. (2011). Unravelling evolutionary strategies of yeast for improving galactose utilization through integrated systems level analysis. Proc. Natl. Acad. Sci. U.S.A. 108, 12179-12184. doi:10.1073/pnas.1103219108

Hottiger, T., Boller, T., and Wiemken, A. (1989). Correlation of trenalose content and heat resistance in yeast mutants altered in the RAS/adenylate cyclase pathway: is trehalose a thermoprotectant? FEBS Lett. 255, 431-434. doi:10.1016/0014-5793(89)81139-1

Hottiger, T., Schmutz, P., and Wiemken, A. (1987). Heat-induced accumulation and futile cycling of trehalose in Saccharomyces cerevisiae. J. Bacteriol. 169, 5518-5522.

Hou, L. (2010). Improved production of ethanol by novel genome shuffling in Saccharomyces cerevisiae. Appl. Biochem. Biotechnol. 160, 1084-1093. doi:10.1007/s12010-009-8552-9

Huang, M., Bai, Y., Sjostrom, S. L., Hallström, B. M., Liu, Z., Petranovic, D., et al. (2015). Microfluidic screening and whole-genome sequencing identifies mutations associated with improved protein secretion by yeast. Proc. Natl. Acad. Sci. U.S.A. 112, E4689-E4696. doi:10.1073/pnas.1506460112

Ibeas, J. I., and Jimenez, J. (1997). Mitochondrial DNA loss caused by ethanol in Saccharomyces flor yeasts. Appl. Environ. Microbiol. 63, 7-12.

Imazu, H., and Sakurai, H. (2005). Saccharomyces cerevisiae heat shock transcription factor regulates cell wall remodeling in response to heat shock. Eukaryot. Cell 4, 1050-1056. doi:10.1128/EC.4.6.1050-1056.2005

Ingesson, H., Zacchi, G., Yang, B., Esteghlalian, A. R., and Saddler, J. N. (2001). The effect of shaking regime on the rate and extent of enzymatic hydrolysis of cellulose. J. Biotechnol. 88, 177-182. doi:10.1016/s0168-1656(01)00273-5

Jacinto, E., and Hall, M. N. (2003). TOR signalling in bugs, brain and brawn. Nat. Rev. Mol. Cell Biol. 4, 117-126. doi:10.1038/nrm1018

Jenkins, G. M., Richards, A., Wahl, T., Mao, C., Obeid, L., and Hannun, Y. (1997). Involvement of yeast sphingolipids in the heat stress response of Saccharomyces cerevisiae. J. Biol. Chem. 272, 32566-32572. doi:10.1074/jbc.272.51.32566

Jones, R. P., and Greenfield, P. F. (1987). Ethanol and the fluidity of the yeast plasma membrane. Yeast 3, 223-232. doi:10.1002/yea.320030403

Jonsson, L., Alriksson, B., and Nilvebrant, N.-O. (2013). Bioconversion of lignocellulose: inhibitors and detoxification. Biotechnol. Biofuels 6, 16. doi:10.1186/1754-6834-6-16

Kajiwara, S., Shirai, A., Fujii, T., Toguri, T., Nakamura, K., and Ohtaguchi, K. (1996). Polyunsaturated fatty acid biosynthesis in Saccharomyces cerevisiae: expression of ethanol tolerance and the FAD2 gene from Arabidopsis thaliana. Appl. Environ. Microbiol. 62, 4309-4313.

Kamada, Y., Jung, U. S., Piotrowski, J., and Levin, D. E. (1995). The protein kinase C-activated MAP kinase pathway of Saccharomyces cerevisiae mediates a novel aspect of the heat shock response. Genes Dev. 9, 1559-1571. doi:10.1101/ gad.9.13.1559

Keating, J. D., Panganiban, C., and Mansfield, S. D. (2006). Tolerance and adaptation of ethanologenic yeasts to lignocellulosic inhibitory compounds. Biotechnol. Bioeng. 93, 1196-1206. doi:10.1002/bit.20838

Keweloh, H., Weyrauch, G., and Rehm, H.-J. (1990). Phenol-induced membrane changes in free and immobilized Escherichia coli. Appl. Microbiol. Biotechnol. 33, 66-71. doi:10.1007/bf00170572

Kim, D., and Hahn, J.-S. (2013). Roles of the Yap1 transcription factor and antioxidants in Saccharomyces cerevisiae's tolerance to furfural and 5-hydroxymethylfurfural, which function as thiol-reactive electrophiles generating oxidative stress. Appl. Environ. Microbiol. 79, 5069-5077. doi:10.1128/aem.00643-13
Kim, I.-S., Kim, Y.-S., Kim, H., Jin, I., and Yoon, H.-S. (2013). Saccharomyces cerevisiae KNU5377 stress response during high-temperature ethanol fermentation. Mol. Cell 35, 210-218. doi:10.1007/s10059-013-2258-0

Kim, S.-K., Jin, Y.-S., Choi, I.-G., Park, Y.-C., and Seo, J.-H. (2015). Enhanced tolerance of Saccharomyces cerevisiae to multiple lignocellulose-derived inhibitors through modulation of spermidine contents. Metab. Eng. 29, 46-55. doi:10.1016/j.ymben.2015.02.004

Klinke, H. B., Thomsen, A. B., and Ahring, B. K. (2004). Inhibition of ethanol-producing yeast and bacteria by degradation products produced during pre-treatment of biomass. Appl. Microbiol. Biotechnol. 66, 10-26. doi:10.1007/ s00253-004-1642-2

Kubota, S., Takeo, I., Kume, K., Kanai, M., Shitamukai, A., Mizunuma, M., et al. (2004). Effect of ethanol on cell growth of budding yeast: genes that are important for cell growth in the presence of ethanol. Biosci. Biotechnol. Biochem. 68, 968-972. doi:10.1271/bbb.68.968

Kültz, D. (2003). Evolution of the cellular stress proteome: from monophyletic origin to ubiquitous function. J. Exp. Biol. 206, 3119-3124. doi:10.1242/jeb.00549

Kültz, D. (2005). Molecular and evolutionary basis of the cellular stress response. Annu. Rev. Physiol. 67, 225-257. doi:10.1146/annurev.physiol.67.040403.103635

Kumari, R., and Pramanik, K. (2012). Improvement of multiple stress tolerance in yeast strain by sequential mutagenesis for enhanced bioethanol production. J. Biosci. Bioeng. 114, 622-629. doi:10.1016/j.jbiosc.2012.07.007

Lam, F. H., Ghaderi, A., Fink, G. R., and Stephanopoulos, G. (2014). Engineering alcohol tolerance in yeast. Science 346, 71-75. doi:10.1126/science.1257859

Larsson, S., Palmqvist, E., Hahn-Hägerdal, B., Tengborg, C., Stenberg, K., Zacchi, G., et al. (1999). The generation of fermentation inhibitors during dilute acid hydrolysis of softwood. Enzyme Microb. Technol. 24, 151-159. doi:10.1016/ S0141-0229(98)00101-X

Larsson, S., Quintana-Sáinz, A., Reimann, A., Nilvebrant, N.-O., and Jönsson, L. (2000). "Influence of lignocellulose-derived aromatic compounds on oxygen-limited growth and ethanolic fermentation by Saccharomyces cerevisiae," in Twenty-First Symposium on Biotechnology for Fuels and Chemicals, eds Finkelstein M. and Davison B. (Fort Collins, Colorado: Humana Press), 617-632.

Lee, K. J., Skotnicki, M. L., Tribe, D. E., and Rogers, P. L. (1980). Kinetic studies on a highly productive strain of Zymomonas mobilis. Biotechnol. Lett. 2, 339-344. doi:10.1007/bf00138666

Lee, K.-M., Kalyani, D., Tiwari, M. K., Kim, T.-S., Dhiman, S. S., Lee, J.-K., et al. (2012). Enhanced enzymatic hydrolysis of rice straw by removal of phenolic compounds using a novel laccase from yeast Yarrowia lipolytica. Bioresour. Technol. 123, 636-645. doi:10.1016/j.biortech.2012.07.066

Lewis, J. A., Elkon, I. M., Mcgee, M. A., Higbee, A. J., and Gasch, A. P. (2010). Exploiting natural variation in Saccharomyces cerevisiae to identify genes for increased ethanol resistance. Genetics 186, 1197-1205. doi:10.1534/ genetics.110.121871

Li, B.-Z., and Yuan, Y.-J. (2010). Transcriptome shifts in response to furfural and acetic acid in Saccharomyces cerevisiae. Appl. Microbiol. Biotechnol. 86, 1915-1924. doi:10.1007/s00253-010-2518-2

Lin, F.-M., Qiao, B., and Yuan, Y.-J. (2009). Comparative proteomic analysis of tolerance and adaptation of ethanologenic Saccharomyces cerevisiae to furfural, a lignocellulosic inhibitory compound. Appl. Environ. Microbiol. 75, 3765-3776. doi:10.1128/aem.02594-08

Lindquist, S. (1981). Regulation of protein synthesis during heat shock. Nature 293, 311-314. doi:10.1038/293311a0

Lindquist, S. (1986). The heat-shock response. Annu. Rev. Biochem. 55, 1151-1191. doi:10.1146/annurev.bi.55.070186.005443

Liu, J.-J., Ding, W.-T., Zhang, G.-C., and Wang, J.-Y. (2011). Improving ethanol fermentation performance of Saccharomyces cerevisiae in very high-gravity fermentation through chemical mutagenesis and meiotic recombination. Appl. Microbiol. Biotechnol. 91, 1239-1246. doi:10.1007/s00253-011-3404-2

Liu, Z. L., Slininger, P., and Gorsich, S. (2005). "Enhanced biotransformation of furfural and hydroxymethylfurfural by newly developed ethanologenic yeast strains," in Twenty-Sixth Symposium on Biotechnology for Fuels and Chemicals, eds Davison B., Evans B., Finkelstein M., and Mcmillan J. (Denver, Colorado: Humana Press), 451-460.

Lu, Y., Cheng, Y.-F., He, X.-P., Guo, X.-N., and Zhang, B.-R. (2012). Improvement of robustness and ethanol production of ethanologenic Saccharomyces cerevisiae under co-stress of heat and inhibitors. J. Ind. Microbiol. Biotechnol. 39, 73-80. doi:10.1007/s10295-011-1001-0 
Luong, J. H. T. (1985). Kinetics of ethanol inhibition in alcohol fermentation. Biotechnol. Bioeng. 27, 280-285. doi:10.1002/bit.260270311

Lushchak, V. I. (2011). Adaptive response to oxidative stress: bacteria, fungi, plants and animals. Comp. Biochem. Physiol. C Toxicol. Pharmacol. 153, 175-190. doi:10.1016/j.cbpc.2010.10.004

Lv, Y.-J., Wang, X., Ma, Q., Bai, X., Li, B.-Z., Zhang, W., et al. (2014). Proteomic analysis reveals complex metabolic regulation in Saccharomyces cerevisiae cells against multiple inhibitors stress. Appl. Microbiol. Biotechnol. 98, 2207-2221. doi:10.1007/s00253-014-5519-8

Lynd, L. R., Cushman, J.H., Nichols, R. J., and Wyman, C. E. (1991). Fuel ethanol from cellulosic biomass. Science 251, 1318-1323. doi:10.1126/science.251.4999.1318

Maris, A. J. A. V., Konings, W. N., Dijken, J. P. V., and Pronk, J. T. (2004). Microbial export of lactic and 3-hydroxypropanoic acid: implications for industrial fermentation processes. Metab. Eng. 6, 245-255. doi:10.1016/j.ymben.2004.05.001

Meena, R., Thakur, S., and Chakrabarti, A. (2011). Regulation of Saccharomyces cerevisiae plasma membrane H+-ATPase (Pma1) by dextrose and Hsp30 during exposure to thermal stress. Indian J. Microbiol. 51, 153-158. doi:10.1007/ s12088-011-0137-y

Miller, E. N., Jarboe, L. R., Yomano, L. P., York, S. W., Shanmugam, K. T., and Ingram, L. O. (2009). Silencing of NADPH-dependent oxidoreductase genes $(y q h D$ and $d k g A)$ in furfural-resistant ethanologenic Escherichia coli. Appl. Environ. Microbiol. 75, 4315-4323. doi:10.1128/aem.00567-09

Mills, C., Child, J. J., and Spencer, J. F. T. (1971). The utilization of aromatic compounds by yeasts. Antonie Van Leeuwenhoek 37, 281-287. doi:10.1007/ bf02218497

Mishra, P., and Prasad, R. (1989). Relationship between ethanol tolerance and fatty acyl composition of Saccharomyces cerevisiae. Appl. Microbiol. Biotechnol. 30, 294-298. doi:10.1007/bf00256221

Mitchell, A., Romano, G. H., Groisman, B., Yona, A., Dekel, E., Kupiec, M., et al. (2009). Adaptive prediction of environmental changes by microorganismssupplementary info available. Nature 460, 220-224. doi:10.1038/nature08112

Nagodawithana, T. W., and Steinkraus, K. H. (1976). Influence of the rate of ethanol production and accumulation on the viability of Saccharomyces cerevisiae in "rapid fermentation". Appl. Environ. Microbiol. 31, 158-162.

Nakanishi, A., Bae, J., Fukai, K., Tukumoto, N., Kuroda, K., Ogawa, J., et al. (2012). Effect of pretreatment of hydrothermally processed rice straw with laccase-displaying yeast on ethanol fermentation. App. Microbiol. Biotechnol. 94, 939-948. doi:10.1007/s00253-012-3876-8

Narendranath, N. V., and Power, R. (2005). Relationship between $\mathrm{pH}$ and medium dissolved solids in terms of growth and metabolism of Lactobacilli and Saccharomyces cerevisiae during ethanol production. Appl. Environ. Microbiol. 71, 2239-2243. doi:10.1128/aem.71.5.2239-2243.2005

Neves, M. J., and Francois, J. (1992). On the mechanism by which a heat shock induces trehalose accumulation in Saccharomyces cervisiae. Biochem. J. 288, 859-864. doi:10.1042/bj2880859

Nwaka, S., Kopp, M., Burgert, M., Deuchler, I., Kienle, I., and Holzer, H. (1994). Is thermotolerance of yeast dependent on trehalose accumulation? FEBS Lett. 344, 225-228. doi:10.1016/0014-5793(94)00385-8

Nwaka, S., Mechler, B., Destruelle, M., and Holzer, H. (1995). Phenotypic features of trehalase mutants in Saccharomyces cerevisiae. FEBS Lett. 360, 286-290. doi:10.1016/0014-5793(95)00105-I

Olsson, L., and Hahn-Hägerdal, B. (1993). Fermentative performance of bacteria and yeasts in lignocellulose hydrolysates. Proc. Biochem. 28, 249-257. doi:10.1016/0032-9592(93)80041-E

Palmqvist, E., Almeida, J. S., and Hahn-Hägerdal, B. (1999a). Influence of furfural on anaerobic glycolytic kinetics of Saccharomyces cerevisiae in batch culture. Biotechnol. Bioeng. 62, 447-454. doi:10.1002/ (SICI) 1097-0290(19990220)62:4<447::AID-BIT7>3.0.CO;2-0

Palmqvist, E., Grage, H., Meinander, N. Q., and Hahn-Hägerdal, B. (1999b). Main and interaction effects of acetic acid, furfural, and p-hydroxybenzoic acid on growth and ethanol productivity of yeasts. Biotechnol. Bioeng. 63, 46-55. doi:10.1002/(SICI)1097-0290(19990405)63:1<46::AID-BIT5>3.3.CO;2-A

Palmqvist, E., and Hahn-Hägerdal, B. (2000a). Fermentation of lignocellulosic hydrolysates. I: inhibition and detoxification. Bioresour. Technol. 74, 17-24. doi:10.1016/S0960-8524(99)00160-1

Palmqvist, E., and Hahn-Hägerdal, B. (2000b). Fermentation of lignocellulosic hydrolysates. II: inhibitors and mechanisms of inhibition. Bioresour. Technol. 74, 25-33. doi:10.1016/S0960-8524(99)00161-3
Pampulha, M. E., and Loureiro-Dias, M. C. (1989). Combined effect of acetic acid, $\mathrm{pH}$ and ethanol on intracellular $\mathrm{pH}$ of fermenting yeast. Appl. Microbiol. Biotechnol. 31, 547-550. doi:10.1007/bf00270792

Pampulha, M. E., and Loureiro-Dias, M. C. (1990). Activity of glycolytic enzymes of Saccharomyces cerevisiae in the presence of acetic acid. Appl. Microbiol. Biotechnol. 34, 375-380. doi:10.1007/bf00170063

Pan, X., Gilkes, N., Kadla, J., Pye, K., Saka, S., Gregg, D., et al. (2006). Bioconversion of hybrid poplar to ethanol and co-products using an organosolv fractionation process: optimization of process yields. Biotechnol. Bioeng. 94, 851-861. doi:10.1002/bit.20905

Panchal, C. J., and Stewart, G. G. (1980). The effect of osmotic pressure on the production and excretion of ethanol and glycerol by a brewing yeast strain. J. Inst. Brew. 86, 207-210. doi:10.1002/j.2050-0416.1980.tb06867.x

Petersson, A., Almeida, J. R. M., Modig, T., Karhumaa, K., Hahn-Hägerdal, B., Gorwa-Grauslund, M. F., et al. (2006). A 5-hydroxymethyl furfural reducing enzyme encoded by the Saccharomyces cerevisiae ADH6 gene conveys HMF tolerance. Yeast 23, 455-464. doi:10.1002/yea.1370

Pinel, D., Colatriano, D., Jiang, H., Lee, H., and Martin, V. (2015). Deconstructing the genetic basis of spent sulphite liquor tolerance using deep sequencing of genome-shuffled yeast. Biotechnol. Biofuels 8,53. doi:10.1186/s13068-015-0241-z

Pinel, D., D’aoust, F., Del Cardayre, S. B., Bajwa, P. K., Lee, H., and Martin, V. J. J. (2011). Saccharomyces cerevisiae genome shuffling through recursive population mating leads to improved tolerance to spent sulfite liquor. Appl. Environ. Microbiol. 77, 4736-4743. doi:10.1128/aem.02769-10

Piper, P. W. (1993). Molecular events associated with acquisition of heat tolerance by the yeast Saccharomyces cerevisiae. FEMS Microbiol. Rev. 11, 339-355. doi:1 0.1111/j.1574-6976.1993.tb00005.x

Piper, P. W., Ortiz-Calderon, C., Holyoak, C., Coote, P., and Cole, M. (1997). Hsp30, the integral plasma membrane heat shock protein of Saccharomyces cerevisiae, is a stress-inducible regulator of plasma membrane H+-ATPase. Cell Stress Chaperones 2, 12-24. doi:10.1379/1466-1268(1997)002<0012: HTIPMH > 2.3.CO;2

Postmus, J., Aardema, R., De Koning, L. J., De Koster, C. G., Brul, S., and Smits, G. J. (2012). Isoenzyme expression changes in response to high temperature determine the metabolic regulation of increased glycolytic flux in yeast. FEMS Yeast Res. 12, 571-581. doi:10.1111/j.1567-1364.2012.00807.x

Postmus, J., Canelas, A. B., Bouwman, J., Bakker, B. M., Van Gulik, W., De Mattos, M. J. T., et al. (2008). Quantitative analysis of the high temperature-induced glycolytic flux increase in Saccharomyces cerevisiae reveals dominant metabolic regulation. J. Biol. Chem. 283, 23524-23532. doi:10.1074/jbc.M802908200

Richard, P., Viljanen, K., and Penttilä, M. (2015). Overexpression of PAD1 and FDC1 results in significant cinnamic acid decarboxylase activity in Saccharomyces cerevisiae. AMB Express 5, 12. doi:10.1186/s13568-015-0103-x

Rodicio, R., and Heinisch, J. J. (2010). Together we are strong - cell wall integrity sensors in yeasts. Yeast 27, 531-540. doi:10.1002/yea.1785

Roosen, J., Engelen, K., Marchal, K., Mathys, J., Griffioen, G., Cameroni, E., et al. (2005). PKA and Sch9 control a molecular switch important for the proper adaptation to nutrient availability. Mol. Microbiol. 55, 862-880. doi:10.1111/j.1365-2958.2004.04429.x

Ruis, H., and Schüller, C. (1995). Stress signaling in yeast. Bioessays 17, 959-965. doi:10.1002/bies.950171109

Sá-Correia, I., and Van Uden, N. (1983). Temperature profiles of ethanol tolerance: effects of ethanol on the minimum and the maximum temperatures for growth of the yeasts Saccharomyces cerevisiae and Kluyveromyces fragilis. Biotechnol. Bioeng. 25, 1665-1667. doi:10.1002/bit.260250620

Sanchez, Y., Taulien, J., Borkovich, K. A., and Lindquist, S. (1992). Hsp104 is required for tolerance to many forms of stress. EMBO J. 11, 2357-2364.

Sárvári Horváth, I., Franzén, C. J., Taherzadeh, M. J., Niklasson, C., and Lidén, G. (2003). Effects of furfural on the respiratory metabolism of Saccharomyces cerevisiae in glucose-limited chemostats. Appl. Environ. Microbiol. 69, 4076-4086. doi:10.1128/aem.69.7.4076-4086.2003

Sasano, Y., Watanabe, D., Ukibe, K., Inai, T., Ohtsu, I., Shimoi, H., et al. (2012). Overexpression of the yeast transcription activator Msn2 confers furfural resistance and increases the initial fermentation rate in ethanol production. J. Biosci. Bioeng. 113, 451-455. doi:10.1016/j.jbiosc.2011.11.017

Scrimale, T., Didone, L., De Mesy Bentley, K. L., and Krysan, D. J. (2009). The unfolded protein response is induced by the cell wall integrity mitogen-activated protein kinase signaling cascade and is required for cell wall integrity 
in Saccharomyces cerevisiae. Mol. Biol. Cell 20, 164-175. doi:10.1091/mbc. E08-08-0809

Shen, Y., Li, H., Wang, X., Zhang, X., Hou, J., Wang, L., et al. (2014). High vanillin tolerance of an evolved Saccharomyces cerevisiae strain owing to its enhanced vanillin reduction and antioxidative capacity. J. Ind. Microbiol. Biotechnol. 41, 1637-1645. doi:10.1007/s10295-014-1515-3

Sehnem, N. T., Da Silva Machado, A., Leite, F. C. B., De Barros Pita, W., De Morais, M. A. Jr., and Ayub, M. A. Z. (2013). 5-hydroxymethylfurfural induces ADH7 and ARI1 expression in tolerant industrial Saccharomyces cerevisiae strain $\mathrm{P} 6 \mathrm{H} 9$ during bioethanol production. Bioresour. Technol. 133, 190-196. doi:10.1016/j. biortech.2013.01.063

Shama, S., Lai, C.-Y., Antoniazzi, J. M., Jiang, J. C., and Jazwinski, S. M. (1998). Heat stress-induced life span extension in yeast. Exp. Cell Res. 245, 379-388. doi:10.1006/excr.1998.4279

Shi, D.-J., Wang, C.-L., and Wang, K.-M. (2009). Genome shuffling to improve thermotolerance, ethanol tolerance and ethanol productivity of Saccharomyces cerevisiae.J. Ind. Microbiol. Biotechnol.36, 139-147. doi:10.1007/s10295-008-0481-z

Shi, L., and Tu, B. P. (2013). Acetyl-CoA induces transcription of the key G1 cyclin CLN3 to promote entry into the cell division cycle in Saccharomyces cerevisiae. Proc. Natl. Acad. Sci. U.S.A. 110, 7318-7323. doi:10.1073/pnas.1302490110

Shin, D. Y., Matsumoto, K., Iida, H., Uno, I., and Ishikawa, T. (1987). Heat shock response of Saccharomyces cerevisiae mutants altered in cyclic AMP-dependent protein phosphorylation. Mol. Cell Biol. 7, 244-250. doi:10.1128/mcb.7.1.244

Singer, M. A., and Lindquist, S. (1998). Thermotolerance in Saccharomyces cerevisiae: the Yin and Yang of trehalose. Trends Biotechnol. 16, 460-468. doi:10.1016/ s0167-7799(98)01251-7

Smith, J., Van Rensburg, E., and Gorgens, J. (2014). Simultaneously improving xylose fermentation and tolerance to lignocellulosic inhibitors through evolutionary engineering of recombinant Saccharomyces cerevisiae harbouring xylose isomerase. BMC Biotechnol. 14:41. doi:10.1186/1472-6750-14-41

Stemmer, W. P. (1994). DNA shuffling by random fragmentation and reassembly: in vitro recombination for molecular evolution. Proc. Natl. Acad. Sci. U.S.A. 91, 10747-10751. doi:10.1073/pnas.91.22.10747

Suutari, M., Liukkonen, K., and Laakso, S. (1990). Temperature adaptation in yeasts: the role of fatty acids. J. Gen. Microbiol. 136, 1469-1474. doi:10.1099/00221287-136-8-1469

Suutari, M., Rintamäki, A., and Laakso, S. (1997). Membrane phospholipids in temperature adaptation of Candida utilis: alterations in fatty acid chain length and unsaturation. J. Lipid Res. 38, 790-794.

Tagkopoulos, I., Liu, Y.-C., and Tavazoie, S. (2008). Predictive behavior within microbial genetic networks. Science 320, 1313-1317. doi:10.1126/ science. 1154456

Taherzadeh, M. J., Gustafsson, L., Niklasson, C., and Lidén, G. (1999). Conversion of furfural in aerobic and anaerobic batch fermentation of glucose by Saccharomyces cerevisiae. J. Biosci. Bioeng. 87, 169-174. doi:10.1016/S1389-1723(99)89007-0

Takahara, T., and Maeda, T. (2012). Transient sequestration of TORC1 into stress granules during heat stress. Mol. Cell 47, 242-252. doi:10.1016/j. molcel.2012.05.019

Tao, X., Zheng, D., Liu, T., Wang, P., Zhao, W., Zhu, M., et al. (2012). A novel strategy to construct yeast Saccharomyces cerevisiae strains for very high gravity fermentation. PLoS ONE 7:e31235. doi:10.1371/journal.pone.0031235

Temple, M. D., Perrone, G. G., and Dawes, I. W. (2005). Complex cellular responses to reactive oxygen species. Trends Cell Biol. 15, 319-326. doi:10.1016/j. tcb.2005.04.003

Tokiwa, G., Tyers, M., Volpe, T., and Futcher, B. (1994). Inhibition of Gl cyclin activity by the Ras/cAMP pathway in yeast. Nature 371, 342-345. doi:10.1038/371342a0
Urban, J., Soulard, A., Huber, A., Lippman, S., Mukhopadhyay, D., Deloche, O., et al. (2007). Sch9 is a major target of TORC1 in Saccharomyces cerevisiae. Mol. Cell 26, 663-674. doi:10.1016/j.molcel.2007.04.020

Verduyn, C., Postma, E., Scheffers, W. A., and Van Dijken, J. P. (1992). Effect of benzoic acid on metabolic fluxes in yeasts: a continuous-culture study on the regulation of respiration and alcoholic fermentation. Yeast 8, 501-517. doi:10.1002/yea.320080703

Verna, J., Lodder, A., Lee, K., Vagts, A., and Ballester, R. (1997). A family of genes required for maintenance of cell wall integrity and for the stress response in Saccharomyces cerevisiae. Proc. Natl. Acad. Sci. U.S.A. 94, 13804-13809. doi:10.1073/pnas.94.25.13804

Viegas, C. A., and Sá-Correia, I. (1991). Activation of plasma membrane ATPase of Saccharomyces cerevisiae by octanoic acid. J. Gen. Microbiol. 137, 645-651. doi:10.1099/00221287-137-3-645

Vilella, F., Herrero, E., Torres, J., and De La Torre-Ruiz, M. A. (2005). Pkcl and the upstream elements of the cell integrity pathway in Saccharomyces cerevisiae, Rom2 and Mtl1, are required for cellular responses to oxidative stress. J. Biol. Chem. 280, 9149-9159. doi:10.1074/jbc.M411062200

Wallace-Salinas, V., and Gorwa-Grauslund, M. (2013). Adaptive evolution of an industrial strain of Saccharomyces cerevisiae for combined tolerance to inhibitors and temperature. Biotechnol. Biofuels 6, 151. doi:10.1186/1754-6834-6-151

Wojda, I., Alonso-Monge, R., Bebelman, J.-P., Mager, W. H., and Siderius, M. (2003). Response to high osmotic conditions and elevated temperature in Saccharomyces cerevisiae is controlled by intracellular glycerol and involves coordinate activity of MAP kinase pathways. Microbiology 149, 1193-1204. doi:10.1099/mic.0.26110-0

Yamamoto, A., Ueda, J., Yamamoto, N., Hashikawa, N., and Sakurai, H. (2007). Role of heat shock transcription factor in Saccharomyces cerevisiae oxidative stress response. Eukaryot. Cell 6, 1373-1379. doi:10.1128/EC.00098-07

Yomano, L. P., York, S. W., and Ingram, L. O. (1998). Isolation and characterization of ethanol-tolerant mutants of Escherichia coli KO11 for fuel ethanol production. J. Ind. Microbiol. Biotechnol. 20, 132-138. doi:10.1038/ sj.jim. 2900496

Yona, A. H., Manor, Y. S., Herbst, R. H., Romano, G. H., Mitchell, A., Kupiec, M., et al. (2012). Chromosomal duplication is a transient evolutionary solution to stress. Proc. Natl. Acad. Sci. U.S.A. 109, 21010-21015. doi:10.1073/ pnas. 1211150109

Zaldivar, J., Martinez, A., and Ingram, L. O. (1999). Effect of selected aldehydes on the growth and fermentation of ethanologenic Escherichia coli. Biotechnol. Bioeng. 65, 24-33. doi:10.1002/ (SICI)1097-0290(19991005)65:1<24::AID-BIT4>3.0.CO;2-2

Zhang, Y.-X., Perry, K., Vinci, V. A., Powell, K., Stemmer, W. P. C., and Del Cardayre, S. B. (2002). Genome shuffling leads to rapid phenotypic improvement in bacteria. Nature 415, 644-646. doi:10.1038/415644a

Conflict of Interest Statement: The authors declare that the research was conducted in the absence of any commercial or financial relationships that could be construed as a potential conflict of interest.

Copyright (C) 2015 Caspeta, Castillo and Nielsen. This is an open-access article distributed under the terms of the Creative Commons Attribution License (CC BY). The use, distribution or reproduction in other forums is permitted, provided the original author(s) or licensor are credited and that the original publication in this journal is cited, in accordance with accepted academic practice. No use, distribution or reproduction is permitted which does not comply with these terms. 